\title{
Global dust optical depth climatology derived from CALIOP and MODIS aerosol retrievals on decadal timescales: regional and interannual variability
}

\author{
Qianqian Song ${ }^{1,2}$, Zhibo Zhang ${ }^{1,2}$, Hongbin $\mathrm{Yu}^{3}$, Paul Ginoux ${ }^{4}$, and Jerry Shen ${ }^{3,5}$ \\ ${ }^{1}$ Physics Department, UMBC, Baltimore, MD, USA \\ ${ }^{2}$ Joint Center of Earth Systems Technology, UMBC, Baltimore, MD, USA \\ ${ }^{3}$ Earth Sciences Division, NASA Goddard Space Flight Center, Greenbelt, MD, USA \\ ${ }^{4}$ NOAA Geophysical Fluid Dynamics Laboratory, Princeton, NJ, USA \\ ${ }^{5}$ College of Computer, Mathematical, and Natural Sciences, University of Maryland, College Park, MD, USA
}

Correspondence: Zhibo Zhang (zhibo.zhang@umbc.edu)

Received: 4 January 2021 - Discussion started: 17 February 2021

Revised: 6 August 2021 - Accepted: 9 August 2021 - Published: 9 September 2021

\begin{abstract}
We derived two observation-based global monthly mean dust aerosol optical depth (DAOD) climatological datasets from 2007 to 2019 with a $2^{\circ}$ (latitude) $\times 5^{\circ}$ (longitude) spatial resolution, one based on Cloud-Aerosol Lidar with Orthogonal Polarization (CALIOP) and the other on Moderate Resolution Imaging Spectroradiometer (MODIS) observations. In addition, the CALIOP climatological dataset also includes dust vertical extinction profiles. Dust is distinguished from non-dust aerosols based on particle shape information (e.g., lidar depolarization ratio) for CALIOP and on dust size and absorption information (e.g., fine-mode fraction, Ångström exponent, and single-scattering albedo) for MODIS, respectively. The two datasets compare reasonably well with the results reported in previous studies and the collocated Aerosol Robotic Network (AERONET) coarse-mode AOD. Based on these two datasets, we carried out a comprehensive comparative study of the spatial and temporal climatology of dust. On a multi-year average basis, the global $\left(60^{\circ} \mathrm{S}-60^{\circ} \mathrm{N}\right)$ annual mean DAOD is 0.032 and 0.067 according to CALIOP and MODIS retrievals, respectively. In most dust-active regions, CALIOP DAOD generally correlates well (correlation coefficient $R>0.6$ ) with the MODIS DAOD, although the CALIOP value is significantly smaller. The CALIOP DAOD is $18 \%, 34 \%, 54 \%$, and $31 \%$ smaller than MODIS DAOD over the Sahara, the tropical Atlantic Ocean, the Caribbean Sea, and the Arabian Sea, respectively. Applying a regional specific lidar ratio (LR) of $58 \mathrm{sr}$ instead
\end{abstract}

of the $44 \mathrm{sr}$ used in the CALIOP operational retrieval reduces the difference from $18 \%$ to $8 \%$ over the Sahara and from $34 \%$ to $12 \%$ over the tropical Atlantic Ocean. However, over eastern Asia and the northwestern Pacific Ocean (NWP), the two datasets show weak correlation. Despite these discrepancies, CALIOP and MODIS show similar seasonal and interannual variations in regional DAOD. For dust aerosol over the NWP, both CALIOP and MODIS show a declining trend of DAOD at a rate of about $2 \% \mathrm{yr}^{-1}$. This decreasing trend is consistent with the observed declining trend of DAOD in the southern Gobi Desert at a rate of $3 \% \mathrm{yr}^{-1}$ and $5 \% \mathrm{yr}^{-1}$ according to CALIOP and MODIS, respectively. The decreasing trend of DAOD in the southern Gobi Desert is in turn found to be significantly correlated with increasing vegetation and decreasing surface wind speed in the area.

\section{Introduction}

Mineral dust, referred to as dust for short, is one of the most abundant type of atmospheric aerosol in terms of dry mass (Textor et al., 2006; Yu et al., 2012; Kok et al., 2017). Dust aerosol directly interacts with both solar and thermal infrared radiation, known as the direct radiative effect, and thereby influences the Earth's radiative energy budget (Kok et al., 2017; Song et al., 2018; Di Biagio et al., 2020). Dust also influences the life cycle and properties of clouds by altering the thermal 
structure of the atmosphere (known as semi-direct effects) (Hansen et al., 1997) and acting as cloud condensation nuclei (CCN) and ice nuclei (IN) (known as indirect effects) (Albrecht, 1989; Rosenfeld and Lensky, 1998; Twomey, 1977). Dust storms and plumes can degrade air quality, affecting human health (Griffin, 2007; Querol et al., 2019). Dust deposition provides essential nutrients to marine and terrestrial ecosystems (Jickells et al., 2005; Yu et al., 2015b) but reduces the snow albedo increasing snowmelt (Painter et al., 2007). All these impacts manifest the important role of mineral dust in the Earth systems (e.g., Evan et al., 2006; Lau and Kim, 2007; Miller and Tegen, 1998; Shao et al., 2011).

Dust production is sporadic in nature. Dust aerosol can be transported on intercontinental, hemispherical, and even global scales (Grousset et al., 2003; Uno et al., 2009; Yu et al., 2012, 2013). Thus, global and routine measurements of dust spanning over years or even decades are vital for studying dust transport and deposition, estimating the dust radiative effects, and evaluating and constraining dust simulations in numerical weather and climate models. Satellite remote sensing is the only means to observe dust on regional to global scales. Satellite remote sensing techniques usually retrieve the optical depth or extinction profile for total aerosol in the atmosphere with additional retrievals of particle size, shape, or absorption properties that are sensor specific. Passive sensors have been used to detect dust sources and track dust plumes at global scales. A few examples are the Total Ozone Mapping Spectrometer (TOMS) (Prospero et al., 2002), Ozone Monitoring Instrument (OMI) (Chimot et al., 2017), Multi-angle Imaging Spectroradiometer (MISR) (Ge et al., 2014; Y. Yu et al., 2019), Moderate Resolution Imaging Spectroradiometer (MODIS) (Ginoux et al., 2010; Remer et al., 2005; Yu et al., 2009), multi-angular and polarimetric POLarization of Directionality of the Earth's Reflectances/Polarization and Anisotropy of Reflectances for Atmospheric science coupled with Observations from a Lidar (POLDER/PARASOL) measurements (Chen et al., 2018) and the Infrared Atmospheric Sounding Interferometer (IASI) (Klüser et al., 2011; Clarisse et al., 2019). On one hand, these passive sensors provide global or quasi-global coverage of column integrated properties of aerosol with satisfactory temporal resolution. On the other hand, they do not provide the vertical structure of aerosol that is critical for studying aerosol-cloud interactions and aerosol influences on the thermal structure of the atmosphere. Space-borne lidar systems, such as the Cloud-Aerosol Lidar with Orthogonal Polarization (CALIOP) aboard the CloudAerosol Lidar and Infrared Pathfinder Satellite Observation (CALIPSO) spacecraft (Winker et al., 2010) and the CloudAerosol Transport System (CATS) aboard the International Space Station (Yorks et al., 2015), are able to provide the vertical structure of aerosol and clouds, albeit with limited spatial coverage. All these passive and active remote sensing observations have been used extensively in studies of the spatial and temporal evolution of aerosol over the past decade (e.g., Proestakis et al., 2018).

A significant hurdle of applying satellite remote sensing measurements for dust studies is how to distinguish dust from other aerosol types in a quantitative way. While many studies have used total aerosol retrievals by focusing on the regions and seasons where dust dominates, some studies have developed sensor-specific methods of partitioning total aerosol into dust and non-dust components with varying assumptions (Kaufman et al., 2005; Kalashnikova et al., 2005; Dubovik et al., 2006; Ginoux et al., 2010; H. Yu et al., 2009, 2013, 2019; Yu et al., 2015a, b). In general, the dust separation methods are based on dust physical and optical properties such as their large size, their irregular or non-spherical shape, and absorption characteristics. For example, CALIOP dust classification is mainly based on the fact that dust aerosols are non-spherical in shape and their lidar depolarization ratio is significantly larger than those spherical aerosols. In contrast, the wide spectral coverage of MODIS measurements enables the retrieval of aerosol particle size information, such as effective radius, fine-mode fraction (FMF), and aerosol extinction Ångström exponent, as well as spectral gradient of absorption (decreasing of absorption from UV to red) (Remer et al., 2005). The combinations of these retrievals provide the basis for dust separation and dust aerosol optical depth (DAOD) retrievals from MODIS. Some recent studies have also characterized dust distribution through integrating satellite measurements with other data sources and model simulations. For example, Voss and Evan (2020) (referred to as VE20 hereafter) developed a dust optical depth record from MODIS retrievals, similar to Kaufman et al. (2005) over the ocean and Ginoux et al. (2012) over land. Unlike Kaufman et al. (2005) and Yu et al. (2020), who derived characteristic FMF values for combustion, dust, and marine aerosol from MODIS retrievals, VE20 determined these characteristic FMFs from Aerosol Robotic Network (AERONET) measurements. VE20 also extended the MODIS-based method to Advanced Very High Resolution Radiometer (AVHRR) overocean retrievals with some assumptions and produced the long-term (1981-2018) record of dust optical depth. Gkikas et al. $(2021)$ developed a global fine-resolution $\left(0.1^{\circ} \times 0.1^{\circ}\right)$ DAOD dataset for the period 2006-2017 by scaling MODISretrieved Collection 6.1 aerosol optical depth (AOD) with the DAOD-to-AOD ratios provided by MERRA-2 (Modern-Era Retrospective analysis for Research and Applications, version 2) reanalysis (Gelaro et al., 2017). Given that MODIS and other remote sensing measurements (e.g., MISR and AERONET) have been assimilated in the MERRA-2 reanalysis to constrain the aerosol optical depth, the DAODto-AOD ratio reported by MERRA-2 is the same as that from the underlying Goddard Chemistry Aerosol Radiation and Transport (GOCART) aerosol transport model in the MERRA-2 reanalysis system.

In this study, we focus on the DAOD derived from CALIOP and MODIS with two major objectives. First, we 
produce a decadal (2007-2019) record of global DAOD and dust vertical extinction coefficient profile climatology from the CALIOP observations, which represents an extension of the transatlantic dust transport and deposition studies by Yu et al. (2015a, b) and H. Yu et al. (2019), both in terms of spatial and temporal coverage. Second, we compare the CALIOP DAOD climatology with the MODIS DAOD over both land and ocean (Yu et al., 2020; Pu and Ginoux, 2018) to identify and understand their differences in terms of global dust distribution and interannual variabilities including trend in key dust regions. Our analysis goes beyond broad dustladen regions by zooming into potential dust source areas, which provides important insights into local dust activities. A systematic comparison and better understanding of DAOD from the two sensors based on distinct retrieval algorithms is critical for applying satellite measurements to evaluate global dust modeling (Kim et al., 2019). In comparison to some more recent studies (Voss and Evan, 2020; Gkikas et al., 2021), our dust climatology is derived using the satellite observations in a self-consistent way without blending in other measurements (e.g., AERONET) or models (e.g., MERRA2). As discussed in Yu et al. (2009), the self-consistent use of MODIS data could minimize the introduction of additional biases due to discrepancies in FMF between MODIS and AERONET. Furthermore, we use the latest version (4.2) CALIOP products and version 6.1 MODIS products to characterize the spatial and temporal distributions of dust. The rest of the paper is organized as follows. Section 2 provides a description of the methodology of deriving dust climatology from CALIOP and MODIS. In Sect. 3, we compare our DAOD datasets with previous studies and collocated AERONET retrievals. In Sect. 4, we compare and study the DAOD climatology from CALIOP and MODIS. Section 5 provides a summary of the study along with the main conclusions.

\section{Dust detection and AOD partition schemes}

\subsection{CALIOP dust detection and AOD partition}

CALIPSO is in a Sun-synchronous polar orbit with an Equator crossing time of around 13:30 LT and $98^{\circ}$ orbit inclination. CALIOP is a two-wavelength (532 and $1064 \mathrm{~nm}$ ) polarization-sensitive lidar aboard CALIPSO. The CALIPSO orbit track repeats every $16 \mathrm{~d}$; the CALIOP sensor never provides global coverage due to its small footprint. At the Earth's surface, the diameter of CALIOP footprint is around $70 \mathrm{~m}$, with spacing distance of $333 \mathrm{~m}$ between two adjacent footprints along the orbit track. CALIOP utilizes three receiver channels (one measuring the $1064 \mathrm{~nm}$ backscatter intensity and two measuring orthogonally polarized components of the $532 \mathrm{~nm}$ backscatter) to provide high vertical resolution $(30-60 \mathrm{~m})$ of aerosol and cloud structure profiles (Winker et al., 2009).
Aerosol subtype classification and a priori assumption of lidar ratio (LR) (extinction-to-backscatter ratio) for specific aerosol type are critical for CALIOP aerosol retrievals. The CALIOP Level 2 product has been validated by comparing with ground-based measurements. The comparison between aerosol subtypes in CALIOP Level 2 V2.01 and NASA AERONET aerosol types shows that $70 \%$ of the CALIOP and AERONET aerosol types are in agreement, and best agreement is achieved for dust and polluted dust (Mielonen et al., 2009). Schuster et al. (2012) compared CALIOP AOD to the collocated AERONET AOD measurements and found a CALIPSO bias of $-13 \%$, corresponding to an absolute bias of -0.029 relative to AERONET AOD on global average. Further comparison between CALIPSO AOD measurements and the collocated AERONET AOD measurements for the columns that contain the dust subtype exclusively showed a larger bias (i.e., $-29 \%$ and corresponding absolute bias of -0.1 ), although they show a relatively high correlation of $R=0.58$; this indicates that the assumed LR of $40 \mathrm{sr}$ for the CALIPSO dust retrievals is too low. Omar et al. (2013) showed that CALIOP AODs are lower than AERONET AODs especially for low AOD. Furthermore, they found that the median of relative AOD difference between CALIOP and AERONET (500 nm) is $25 \%$ of AERONET AOD for AOD $>0.1$.

CALIOP observations have been used widely in previous studies of the spatial and temporal evolution of dust aerosols over the past decade (Huang et al., 2007, 2008; Yang et al., 2012; Xu et al., 2016; Kim et al., 2019). It is important to note that these studies are regional in scope and they use the standard CALIPSO product and aerosol subtype classification algorithm (Omar et al., 2009). In the standard CALIPSO product, each detected aerosol layer is classified as one of the six subtypes: dust, polluted dust, polluted continental, smoke, clean marine, and clean continental. In the latest CALIOP version, another subtype (marine dust) is introduced (Kim et al., 2018). In these studies, the "dust" subtype or a combination of "dust" and "polluted dust" subtypes is categorized as dust. While the former assumption leads to an underestimate of dust due to neglecting dust component in the "polluted dust" subtype, the latter assumption results in an overestimate of dust because of accounting for non-dust component in the "polluted dust" subtype. In order to better distinguish dust component from each CALIOP-detected aerosol layer, $\mathrm{Yu}$ et al. (2015a) developed an algorithm independent of the standard aerosol subtype classification to distinguish dust from non-dust aerosol by using their respective thresholds of particulate depolarization ratio (Table 1). The depolarizationbased dust separation algorithm is based on the method developed by Shimizu et al. (2004), Hayasaka et al. (2007), and Tesche et al. (2009). The algorithm has been implemented in the framework of surface lidar networks such as the European Aerosol Research Lidar Network (EARLINET) (Ansmann et al., 2011) and also applied to CALIOP observations (Yu et al., 2012; Amiridis et al., 2013; Yu et al., 2015a). 
They further used the derived three-dimensional distribution of dust extinction to quantify the transatlantic dust transport and deposition and its implications for the Amazon rainforest (Yu et al., 2015b; H. Yu et al., 2019).

In this study, we use the methodology in Yu et al. (2015a) to derive the monthly mean dust extinction profile under clear-sky conditions from the latest (V4.20) CALIOP products on a global scale from 2007 to 2019. First, we select the cloud-free columns based on the CALIOP cloud layer product. In order to increase the sampling, we define clear-sky cases in this study either as columns that are completely cloud-free or with the presence of optically thin (cloud optical depth $<0.2$ ) and high-level (cloud base $>7 \mathrm{~km}$ ) clouds. This is justified, as the presence of high-level optically thin clouds does not significantly affect the retrieval of aerosol layers below the clouds (Yu et al., 2015a). After clear-sky screening, we use the operational $5 \mathrm{~km}$ Level 2 CALIOP aerosol profile product that contains aerosol depolarization, backscatter, and extinction profiles over a global scale (Young et al., 2018) to derive the dust extinction profile. The depolarization ratio from CALIOP is a key variable for detecting and distinguishing dust from non-dust aerosol. Backscatter by spherical particle largely retains the polarization of the incident light, resulting in a depolarization ratio of nearly zero. In contrast, dust particles are generally nonspherical in shape and large in size, which gives them nonzero depolarization ratio that is significantly larger than other types of aerosol. The cloud-aerosol discrimination (CAD) score in the products gauges the level of confidence for a feature being classified as aerosol or cloud. In this study, in order to screen out low-confidence aerosol and cloud discrimination, we select layers with CAD scores between -90 and -100 (high level of confidence for aerosol feature) by following $\mathrm{H}$. Yu et al. (2019). The aerosol profile product also provides an extinction quality control flag (Ext_QC) to indicate problematic retrievals. This study only uses layers with Ext_QC values of 0, 1, 18, and 16 (Winker et al., 2013). Only nighttime data are used to avoid sunlight interference in aerosol signals.

For each aerosol backscatter coefficient profile, we derive the fraction of dust backscatter to total backscatter $\left(f_{\mathrm{d}}\right)$ at each altitude from the following equation:

$f_{\mathrm{d}}=\frac{\left(\delta-\delta_{\mathrm{nd}}\right)\left(1+\delta_{\mathrm{d}}\right)}{\left(\delta_{\mathrm{d}}-\delta_{\mathrm{nd}}\right)(1+\delta)}$,

where $\delta$ is CALIOP observed particulate depolarization ratio, $\delta_{\mathrm{d}}$ and $\delta_{\text {nd }}$ are a priori knowledge of depolarization ratios of dust and non-dust aerosols respectively. Clearly, the calculations of $f_{\mathrm{d}}$ in Eq. (1) rely on the a priori depolarization ratios of dust and non-dust aerosols (i.e., $\delta_{\mathrm{d}}$ and $\delta_{\text {nd }}$ ). To account for various types of non-dust aerosols with different depolarization ratio, we follow Yu et al. (2015a) and assume 0.02 and 0.07 as lower and upper bounds for $\delta_{\text {nd }}$ (Burton et al., 2012; Fiebig et al., 2002; Sakai et al., 2010). Dust aerosols have a significantly larger depolarization ra- tio compared to non-dust aerosols. To account for the variability of dust shape and size, we use 0.2 and 0.3 as lower and upper bounds for $\delta_{\mathrm{d}}$ (Ansmann et al., 2012; Esselborn et al., 2009; Sakai et al., 2010). Given an observed dust depolarization ratio $\delta$, the $f_{\mathrm{d}}$ based on Eq. (1) has the minimum value when $\delta_{\mathrm{d}}=0.30$ and $\delta_{\mathrm{nd}}=0.07$ and the maximum value when $\delta_{\mathrm{d}}=0.20$ and $\delta_{\text {nd }}=0.02$. To account for this variability, the final $f_{\mathrm{d}}$ is based on the mean of the lowest (i.e., $\delta_{\mathrm{d}}=0.30$ and $\delta_{\text {nd }}=0.07$ ) and the highest (i.e., $\delta_{\mathrm{d}}=0.20$ and $\delta_{\mathrm{nd}}=0.02$ ) dust scenario.

In each $2^{\circ}$ (latitude) $\times 5^{\circ}$ (longitude) grid, at each altitude, dust backscatter coefficient for per clear-sky overpass is derived by multiplying CALIOP total backscatter coefficient with the calculated $f_{\mathrm{d}}$ from Eq. (1). To derive dust extinction coefficient from dust backscatter coefficient, we assume dust LR, i.e., extinction-to-backscatter ratio, of $44 \pm 9 \mathrm{sr}$ at $532 \mathrm{~nm}$, consistent with CALIOP version 4.20 operational retrieval (Kim et al., 2018). The monthly mean dust extinction coefficient is calculated at each altitude when overpass samples within the month are larger than five. Then DAOD is calculated by integrating the monthly mean extinction coefficient profile for each grid. The use of globally uniform LR and the selection of $\delta_{\mathrm{d}}$ and $\delta_{\text {nd }}$ could induce uncertainty to the derived DAOD. This is discussed in Sect. 3 .

It is important to note that in this study we use only nighttime CALIOP observations for DAOD retrievals. This is because the daytime CALIOP observations are often contaminated by background solar noise (Getzewich et al., 2018). As shown in Fig. S1 in the Supplement, when the above DAOD retrieval method is applied to daytime CALIOP observation, there is a widespread non-zero DAOD retrieval over remote ocean regions where dust should be scarce. This is apparently an artifact caused by solar contamination on CALIOP daytime observations, which motivates and justifies our use of nighttime CALIOP observations. On the other hand, this leads to an inconsistency with the MODIS DAOD retrieval which is based on daytime observations (see Sect. 2.2). Although the diurnal cycle of dust has been investigated using model simulations (e.g., Yue et al., 2009), it is extremely difficult to assess dust diurnal variation from polar-orbiting remote sensing observations, especially using elastic lidar in visible region like CALIOP, due to the inherent instrument limitation. For example, a recent study by Y. Yu et al. (2021) attempted to use the retrievals from the Cloud-Aerosol Transport System (CATS) lidar to study the diurnal cycle of dust. The $51.6^{\circ}$ inclination orbit allows CATS to sample the tropical and midlatitude regions multiple times a day, which make it more advantageous than CALIOP for diurnal variability studies. Unfortunately, after a validation comparison with AERONET observations (i.e., solar-based during daytime and lunar-based during nighttime), they found a significant day-night inconsistency in their retrieval quality. Because of this inconsistency, they concluded that diurnal variability in dust and dust mixture characteristics has to be examined separately for daytime and nighttime periods. Nevertheless, 
Table 1. Summary of DAOD retrievals from MODIS and CALIOP.

\begin{tabular}{llll}
\hline Sensors & Retrieve scope & Relevant variables used to derive DAOD & References \\
\hline MODIS & Ocean & AOD, fine-mode AOD & Yu et al. (2009, 2020) \\
MODIS & Land & AOD, SSA at 470 nm, Angström exponent & Pu and Ginoux et al. (2018) \\
CALIOP & Globe & Profiles of backscatter, extinction, depolarization ratio & Yu et al. (2015a) \\
\hline
\end{tabular}

Y. Yu et al. (2021) plotted the daytime and nighttime DAOD together for several dust-active regions (see their Figs. 3 and 10-13). The contrast between daytime and nighttime DAOD based on these plots is roughly between $10 \%-15 \%$, which is smaller than other uncertainties in CALIOP retrievals as analyzed in Sect. 3. Again, it has to be emphasized that this contrast is partly due to the day-night inconsistency in CATS data quality.

\subsection{MODIS dust detection and AOD partition}

As described above, the CALIOP-based DAOD derivation mainly makes use of dust non-sphericity in shape to separate dust aerosol from others. Another important difference of dust aerosol from other types of aerosols is their relatively large size. This difference provides the basis for the dust separation. The DAOD derivation scheme based on MODIS retrievals is introduced in this section.

MODIS sensors aboard the Aqua and Terra satellites measure radiances at 36 spectral bands ranging from 0.41 to $14 \mu \mathrm{m}$, with a $2330 \mathrm{~km}$ swath that provides near-global coverage every day. MODIS aerosol retrievals employ two complementary algorithms to achieve the global coverage. The Dark Target (DT) algorithm is applicable for the retrieval of aerosol loading and properties over dark surfaces, including ocean water and vegetated land. The MODIS aerosol AOD retrievals over the ocean are found within the retrieval errors of $\Delta \tau_{\mathrm{a}}= \pm 0.03 \pm 0.05 \tau_{\mathrm{a}}$ relative to AERONET AOD measurements (Remer et al., 2005). An approach was developed in previous studies to separate DAOD from other types of aerosol by using aerosol optical depth $(\tau)$ and finemode fraction $(f)$ retrieved from MODIS DT retrieval over the ocean. Both $\tau$ and $f$ refer to properties at $550 \mathrm{~nm}$ hereafter, unless specified otherwise. In this approach, both $\tau$ and fine-mode AOD $(f \tau)$ are assumed to be composed of marine aerosol, dust, and combustion aerosols, i.e.,

$\tau=\tau_{\mathrm{m}}+\tau_{\mathrm{d}}+\tau_{\mathrm{c}}$,

$f \tau=f_{\mathrm{m}} \tau_{\mathrm{m}}+f_{\mathrm{d}} \tau_{\mathrm{d}}+f_{\mathrm{c}} \tau_{\mathrm{c}}$,

where the subscripts $\mathrm{m}, \mathrm{d}$, and $\mathrm{c}$ represent marine aerosol, dust, and combustion aerosol, respectively. Based on Eqs. (2) and (3), $\tau_{\mathrm{d}}$ can be calculated from MODIS-retrieved $\tau$ and $f$, with appropriate parameterizations for $f_{\mathrm{m}}, f_{\mathrm{d}}, f_{\mathrm{c}}$, and $\tau_{\mathrm{m}}$. More specifically, $f_{\mathrm{m}}, f_{\mathrm{d}}$, and $f_{\mathrm{c}}$ were determined from retrieved $f$ in selected regions and seasons for which a specific aerosol type dominates, and $\tau_{\mathrm{m}}$ was parameterized as a func- tion of wind speed (details can be found in Kaufman et al., 2005; Yu et al., 2009, 2020).

Over land, MODIS aerosol properties including AOD, the Ångström exponent, and single-scattering albedo (SSA) are retrieved from the Deep Blue (DB) algorithm (Hsu et al., 2004, 2013). The MODIS aerosol AOD retrievals over land are found within the retrieval errors of $\Delta \tau_{\mathrm{a}}= \pm 0.05 \pm 0.15 \tau_{\mathrm{a}}$ relative to AERONET AOD measurements (Remer et al., 2005). DAOD over land is derived from the AOD using one criterion based on size distribution (to distinguish fine and coarse modes) and the other criterion based on absorption (to distinguish between scattering sea salt and absorbing dust). To apply the first criterion, we use the following formula established by Anderson et al. (2005) using in situ data:

$\mathrm{COD}_{\mathrm{M}}=\mathrm{AOD} \times\left(0.98-0.5089 \alpha+0.051 \alpha^{2}\right)$,

where $\alpha$ is the Angström exponent (a measure of the wavelength dependence of optical depth) which has been shown to be highly sensitive to particle size (Eck et al., 1999), $\mathrm{COD}_{\mathrm{M}}$ is the coarse-mode fraction (aerodynamic diameters larger than $1 \mu \mathrm{m})$ of AOD retrieved from MODIS, with a contribution from absorbing (DAOD) and scattering aerosols (sea salt aerosol optical depth). The second criterion requires the single-scattering albedo at $470 \mathrm{~nm}$ to be less than 0.99 for the retrieval of DAOD (more details can be found in Pu and Ginoux, 2018).

Overall, multi-wavelength observations from MODIS contain aerosol size information such as fine-mode fraction and Ångström exponent in the observed reflectance spectral pattern, which was used to separate dust aerosol from others in MODIS dust retrieval over the ocean and land (Table 1). In this study, the latest retrieved aerosol properties from MODIS Collection 6.1 are used. We use data from Aqua MODIS only, because Terra MODIS retrievals may generate spurious dust trend (Yu et al., 2020). In order to minimize cloud contamination and avoid the infrequent sampling to bias DAOD in MODIS dust retrieval over the ocean, we screen the data by requiring a minimum of 10 DAOD retrievals in a month.

The relevant variables and the quality assurance procedures used in CALIOP- and MODIS-based DAOD retrievals are summarized in Tables 1 and S1 in the Supplement, respectively. 


\section{Comparison with previous studies and uncertainty analysis}

Based on the dust detection and separation schemes of two sensors described in Sect. 2, we derived the following three datasets: the monthly mean CALIOP-based total aerosol optical depth (TAOD) and DAOD, as well as the vertical extinction profile on a $2^{\circ}$ (latitude) $\times 5^{\circ}$ (longitude) spatial resolution grids for the period of 2007-2019. This relatively coarse resolution is limited by CALIOP's sampling.

We combine the monthly mean Aqua MODIS over-ocean (Yu et al., 2020) and over-land (Pu and Ginoux, 2018) TAOD and DAOD on a $1^{\circ} \times 1^{\circ}$ spatial resolution grids to get the monthly mean MODIS-based TAOD and DAOD from 2003 to 2019. In order to compare with CALIOP-based dust climatology data, we aggregate the $1^{\circ} \times 1^{\circ}$ MODIS-based data to $2^{\circ} \times 5^{\circ}$ resolution grids.

For evaluation and comparison purpose (see Sect. 4.1), we also produce a seasonal global distribution of conditionally sampled DAOD from CALIOP (Marinou et al., 2017; Proestakis et al., 2018). While the standard climatological DAOD includes all cloud-free cases in the average of dust extinction and DAOD regardless of the presence of dust, the conditionally sampled DAOD calculation only averages those cases where dust is detected (i.e., DAOD and dust extinction are non-zero). Therefore, the conditionally sampled DAOD is directly related to the intensity of the detected dust events, whereas the climatological DAOD is determined by a number of factors including not only the intensity of the detected dust events but also the frequency of the dust events as well as the capability of the instrument to sample the dust events.

\subsection{Comparison with previous studies}

Before we compare and study the DAOD climatology from MODIS and CALIOP in detail in the next section, we first evaluate our retrievals through comparisons with the regional and global DAOD values reported in the previous studies and explore the potential reasons for the differences.

Table 2 summarizes a comprehensive comparison of our DAOD datasets with previous studies. In Ridley et al. (2016), DAOD is first estimated in 14 dust-laden regions from the combination of AERONET measurements, MODIS, and MISR retrievals. Then the observation-based regional DAOD estimates are estimated to the global scale based on the model-estimated regional-to-global DAOD ratio. Using this method, they estimated that the global $\left(90^{\circ} \mathrm{S}-90^{\circ} \mathrm{N}\right)$ DAOD at $550 \mathrm{~nm}$ is $0.03 \pm 0.005$. Using the DAOD-to-AOD ratio from MERRA-2, Gkikas et al. (2021) converted the MODIS AOD retrievals to DAOD and found a similar global $\left(90^{\circ} \mathrm{S}-\right.$ $\left.90^{\circ} \mathrm{N}\right) \mathrm{DAOD}$ at $550 \mathrm{~nm}$ around 0.033 . In contrast, as shown in Table 2, our MODIS-based global $\left(90^{\circ} \mathrm{S}-90^{\circ} \mathrm{N}\right)$ DAOD is 0.057 . However, it is important to note that the global mean DAOD values from these studies are not directly comparable to our global mean results because of the methodology differences. In particular, both of the aforementioned studies used model simulations to aid their global DAOD estimate, while our estimates are completely based on observations (more precisely, DAODs of the scope $60^{\circ} \mathrm{S}-60^{\circ} \mathrm{N}$ are completely based on observations, while outside of the scope, DAOD is assumed to be zero). Nevertheless, to gain a more insightful understanding of the differences, we select the same 14 dust-laden regions as in Ridley et al. (2016) (see Fig. S2) and derive the corresponding regional DAOD (see Fig. S3 and Table S2). As mentioned previously, in Ridley et al. (2016), the DAOD in these dust-laden regions is based on AERONET measurements and satellite retrievals, and therefore it is more comparable with our results. As shown in the Supplement (Fig. S3), our regional MODIS-based DAOD values are in excellent agreement with those reported in Ridley et al. (2016) (relative bias $B_{\mathrm{r}}=-5.8 \%$ in DJF, $-0.2 \%$ in MAM, $-2.5 \%$ in JJA, and $-10.4 \%$ in SON). This regional comparison suggests that the difference in global DAOD between our study and Ridley et al. (2016) is probably because we used different methods to derive the DAOD in the regions with less frequent dust activities (i.e., observation based vs. model based).

Recently, VE20 used a method similar to our MODISbased DAOD estimate methodology to derive the global DAOD. Because of the use of similar methodology and data, VE20 is more comparable to our study than Ridley et al. (2016) or Gkikas et al. (2021). They estimated the longterm mean DAOD to be 0.1 over land between $50^{\circ} \mathrm{S}$ and $60^{\circ} \mathrm{N}$, which is almost identical to our estimate of 0.103 $\left(60^{\circ} \mathrm{S}-60^{\circ} \mathrm{N}\right)$, as shown in Table 2. However, when averaged over the ocean, their DAOD estimate $(0.03 \pm 0.01)$ is significantly smaller than our result (0.055). As explained in the Supplement, this difference is probably because different parameterizations of $f_{\mathrm{m}}, f_{\mathrm{d}}, f_{\mathrm{c}}$, and $\tau_{\mathrm{m}}$ in Eq. (3) were used in the two studies (see Table S4 and discussions in the Supplement).

A recent study by Proestakis et al. (2018) used a method similar to ours, as described in Sect. 2.1, to derive CALIOPbased regional DAOD in five dust-laden regions in Asia. We compared our CALIOP-based regional DAOD for the same regions (Fig. S4) and compare the results with the values reported in Proestakis et al. (2018). As shown in Fig. S5, the two studies are in excellent agreement with relative difference $B_{\mathrm{r}}=5.5 \%$ in DJF, $-6.0 \%$ in MAM, $-6.9 \%$ in JJA, and $0.8 \%$ in SON, respectively.

Overall, the above comparisons indicate that our DAOD retrievals are in reasonable agreement with previous studies (where directly comparable). However, none of the aforementioned previous studies performed a systematic comparison between MODIS- and CALIOP-based DAOD, which is one of the motivations for this study and will be addressed in Sect. 4. 
Table 2. Compare global mean DAOD retrievals in this study with some relevant studies (note that the definition of global scope is different for different studies).

\begin{tabular}{|c|c|c|c|}
\hline Region & & DAOD at $550 \mathrm{~nm}$ & Reference \\
\hline $90^{\circ} \mathrm{S}-90^{\circ} \mathrm{N}$ & Global & $0.03 \pm 0.005$ & $\begin{array}{l}\text { Ridley et al. (2016): } \\
\text { use multiple satellite platforms, in situ AOD observations, and four global } \\
\text { models }\end{array}$ \\
\hline $90^{\circ} \mathrm{S}-90^{\circ} \mathrm{N}$ & Global & 0.033 & $\begin{array}{l}\text { Gkikas et al. (2021): } \\
\text { use AOD from Aqua MODIS and DAOD-to-AOD ratio from MERRA-2 }\end{array}$ \\
\hline \multirow[t]{2}{*}{$50^{\circ} \mathrm{S}-60^{\circ} \mathrm{N}$} & Over ocean & $0.03 \pm 0.06$ & $\begin{array}{l}\text { Voss and Evan (2020) } \\
\text { over ocean: use method in Kaufman et al. (2005) } \\
\text { over land: use method in Ginoux et al. (2012) }\end{array}$ \\
\hline & Over land & 0.1 & \\
\hline \multirow[t]{3}{*}{$60^{\circ} \mathrm{S}-60^{\circ} \mathrm{N}$} & Over ocean & $0.055,0.020$ & This study: \\
\hline & & & $\begin{array}{l}\text { MODIS-based, CALIOP-based DAOD } \\
\text { (to calculate global mean DAOD for scope } 90^{\circ} \mathrm{S}-90^{\circ} \mathrm{N} \text {, we assume zero } \\
\text { DAOD outside of the region } 60^{\circ} \mathrm{S}-60^{\circ} \mathrm{N} \text {. We weight each grid-cell surface } \\
\text { area into ocean, land, and global DAOD averages) }\end{array}$ \\
\hline & Over land & $0.103,0.068$ & \\
\hline $90^{\circ} \mathrm{S}-90^{\circ} \mathrm{N}$ & Global & $0.057,0.028$ & \\
\hline
\end{tabular}

\subsection{Uncertainty analysis}

In order to understand the differences between the MODISand CALIOP-based DAOD, it is important to identify and quantify the uncertainties in each retrieval. The uncertainty of CALIOP DAOD retrieval comes from several sources: an important source is the inherent uncertainty associated with CALIOP observations and its retrieval algorithm, such as instrument calibration errors (Kar et al., 2018), errors in discriminating cloud from aerosol, and failure to detect aerosol layers (including tenuous aerosol layer and the lower part of heavy dust layer. For example, Thorsen and Fu (2015) estimated that CALIOP may have underestimated 30\%-50\% in the magnitude of aerosol direct radiative effect due to its low sensitivity to tenuous layer), which is likely to translate into low bias in DAOD. In heavy aerosol conditions (e.g., strong dust storms in source regions and outflow regions), the CALIOP laser cannot penetrate to the bottom of aerosol layer due to the laser attenuation (Rajapakshe et al., 2017), which could also lead to a low bias in CALIOP DAOD.

CALIOP-based DAOD is also subject to the uncertainty associated with the assumed dust LR. Different deserts produce dust with different mineralogy, size, and shape, and thus different LRs. Voss et al. (2001) measures LR for African dust as $41 \pm 8$ sr using a micropulse lidar system and Liu et al. (2002) measures LR for Asian dust as 42-55 sr. Globally observed LRs are summarized in Müller et al. (2007) and Baars et al. (2016). In this study, we assume dust LR to be $44 \pm 9 \mathrm{sr}$ at $532 \mathrm{~nm}$ to be consistent with the value used in the CALIOP V4 product (Kim et al., 2018). This LR range is also comparable to previous studies and basically covers the range of typical dust LRs from 35 to $55 \mathrm{sr}$ (Müller et al., 2007; Baars et al., 2016). The \pm 9 sr induces $\pm 20 \%$ DAOD uncertainties. When separating dust from non-dust aerosol, the choice of depolarization ratio (DPR) for dust aerosols and non-dust aerosols also introduces uncertainty in DAOD. To quantify the uncertainty caused by DPR selection, we also calculated DAOD in the lowest $\left(\delta_{\mathrm{d}}=0.30\right.$ and $\left.\delta_{\text {nd }}=0.07\right)$ and the highest $\left(\delta_{\mathrm{d}}=0.20\right.$ and $\left.\delta_{\mathrm{nd}}=0.02\right)$ dust fraction scenarios. The uncertainty induced by DPR is region dependent (Fig. S6). The uncertainty is much lower in dust-dominant regions than other regions. The averaged uncertainty for regions with DAOD $>0.05$ is $20 \%$, while the averaged uncertainty for other regions is $38 \%$.

MODIS dust detection is also subject to a number of uncertainties. Over the ocean, the persistent presence of clouds, especially broken clouds, poses a great challenge to the MODIS aerosol retrievals (Martins et al., 2002). If a cloud is mistaken as aerosol, it would lead to a high AOD and low FMF bias, and thereby a high DAOD bias. In addition, DAOD was calculated from the MODIS-retrieved AOD $(\tau)$ and FMF $(f)$ with appropriate parameterizations of marine aerosol AOD $\left(\tau_{\mathrm{m}}\right)$, FMF of dust $\left(f_{\text {dust }}\right)$, combustion $\left(f_{\mathrm{c}}\right)$, and marine $\left(f_{\mathrm{m}}\right)$ aerosols (see Table 2 in Yu et al., 2020, for the parameterization values). All the parameterizations could also introduce uncertainty in the derived DAOD, in particular on a regional basis (see details in Yu et al., 2020). Over 
land, the derived MODIS DAOD represents the coarse-mode fraction (aerodynamic diameters larger than $1 \mu \mathrm{m}$ ) of dust only. The exclusion of submicron dust aerosol could induce around $3 \%$ underestimation of the global atmospheric dust mass load and around $15 \%$ underestimation of the global DAOD (see Fig. S1 in Kok et al., 2017).

One way to evaluate these uncertainties and validate the two dust detection methods is to compare them with an independent measurement of DAOD. AERONET measurements have been considered as ground truth and often used to evaluate satellite aerosol optical depth retrievals. However, so far, there is no valid method to derive DAOD from AERONET AOD measurements to compare our results with. Therefore, we use coarse-mode AOD (COD) from AERONET measurements as a proxy for DAOD (Pu and Ginoux, 2018) to compare with our DAOD datasets and further estimate the absolute expected errors (EEs) associated with our DAOD datasets. The fine-mode and coarse-mode AODs in AERONET product are defined optically rather than in terms of a microphysical cutoff of the associated particle size distribution at some specific radius (see details in O'Neill et al., 2003). Over land, especially dust source regions, dust aerosols are predominantly in coarse mode; therefore, AERONET COD could be considered as a good proxy of DAOD over land. Over the ocean, the exclusion of finemode DAOD could be partially canceled by the inclusion of coarse sea salt AOD in AERONET COD retrievals. Therefore, AERONET COD is considered as a proxy of DAOD over the ocean as well.

We use AERONET monthly mean COD retrieved at $500 \mathrm{~nm}$ from the level 2 (cloud-screened and quality-assured) spectral deconvolution algorithm (SDA) version 4.1 in this study. The AERONET COD is converted to 550 and $532 \mathrm{~nm}$ using the Angström exponent to compare with MODIS and CALIOP DAOD retrievals, respectively. In addition, we produce a finer-resolution $\left(1^{\circ} \times 1^{\circ}\right)$ CALIOP-based DAOD retrieval to compare with AERONET COD.

For overland dust retrievals, between 2007 and 2019, there are 16653 MODIS, CALIOP monthly mean DAOD retrievals collocated with 761 AERONET sites located within a $1^{\circ}$ MODIS and CALIOP grid cell (Fig. 1). MODIS DAOD $\left(\mathrm{DAOD}_{\mathrm{M}}\right)$ is overall biased high compared to AERONET COD with absolute bias $B_{\mathrm{a}}=0.01$ and relative bias $B_{\mathrm{r}}=$ $26.7 \%$, while CALIOP DAOD $\left(\right.$ DAOD $\left._{\mathrm{C}}\right)$ is generally biased low with $B_{\mathrm{a}}=-0.02$ and $B_{\mathrm{r}}=-27.9 \%$. Using a methodology suggested in Sayer et al. (2013), the estimated EE (take 68th percentiles referring to Sayer et al., 2013) for all collocated MODIS DAOD over land is approximately $0.65 \times \mathrm{DAOD}_{\mathrm{M}}+0$, and for CALIOP DAOD over land it is approximately $0.52 \times \mathrm{DAOD}_{\mathrm{C}}+0.02$ (Fig. 2).

For over-ocean dust retrievals, between 2007 and 2019, there are 7755 MODIS, CALIOP monthly mean DAOD retrievals collocated with 311 AERONET sites located within a $1^{\circ}$ MODIS and CALIOP grid cell (Fig. 3). MODIS DAOD is overall biased high compared with AERONET
COD with absolute bias $B_{\mathrm{a}}=0.01$ and relative bias $B_{\mathrm{r}}=$ $18.1 \%$, while CALIOP DAOD is generally biased low with $B_{\mathrm{a}}=-0.02$ and $B_{\mathrm{r}}=-35 \%$. The estimated $\mathrm{EE}$ for all collocated MODIS DAOD over land is approximately $0.50 \times \mathrm{DAOD}_{\mathrm{M}}+0$, and for CALIOP DAOD over land it is approximately $0.54 \times$ DAOD $_{\mathrm{C}}+0.02$ (Fig. 4).

We further analyze the statistical parameters and EE by continent for MODIS and CALIOP DAOD (Table 3). The lowest $\mathrm{EE}\left(B_{\mathrm{r}}\right)$ and highest correlation $(R)$ are estimated over Africa, followed by Asia, Europe, the Americas, and Australia. This implies that our DAOD retrievals are subject to higher bias under high AOD in polluted regions. Overall, MODIS-based monthly mean DAOD retrievals are larger than AERONET COD measurements, while CALIOPbased DAOD retrievals are smaller than AERONET COD, which seems to suggest that the true DAODs fall between the MODIS and CALIOP DAOD products.

\section{Global dust climatology}

In this section, we compare CALIOP global dust retrieval against MODIS dust retrieval, more specifically MODIS ocean dust retrieval from Yu et al. $(2009,2020)$ and land dust retrieval from Pu and Ginoux (2018); we analyze the similarities and differences between two dust climatological datasets and furthermore study the seasonal cycle and trend of dust aerosols based on these datasets.

\subsection{Comparison between CALIOP and MODIS DAOD climatology}

The DAOD climatology datasets derived from the CALIOP and MODIS observations, as described in Sect. 3, have two major sources of uncertainty:

1. The first is the uncertainty associated with the TAOD retrieval. The primary uncertainty sources in MODIS TAOD retrieval include instrument calibration errors, cloud-masking errors, inappropriate assumption of surface reflectance, and aerosol model selection (Remer et al., 2005; Levy et al., 2013, 2018). Uncertainty sources in CALIOP aerosol retrieval include instrument calibration errors, errors in discriminating cloud from aerosol, uncertainties associated with the a priori assumption of LRs, underdetection of tenuous aerosol layers, and overestimation of the elevation height of heavy aerosol plume base (Winker et al., 2009; Yu et al., 2010; Schuster et al., 2012; Thorsen and Fu, 2015; Rajapakshe et al., 2017).

2. The second is the uncertainty associated with dust detection and separation. As explained in Sect. 2, CALIOP- and MODIS-based dust detection and separation methods are based on different characteristics of dust aerosols in comparison with other types of 

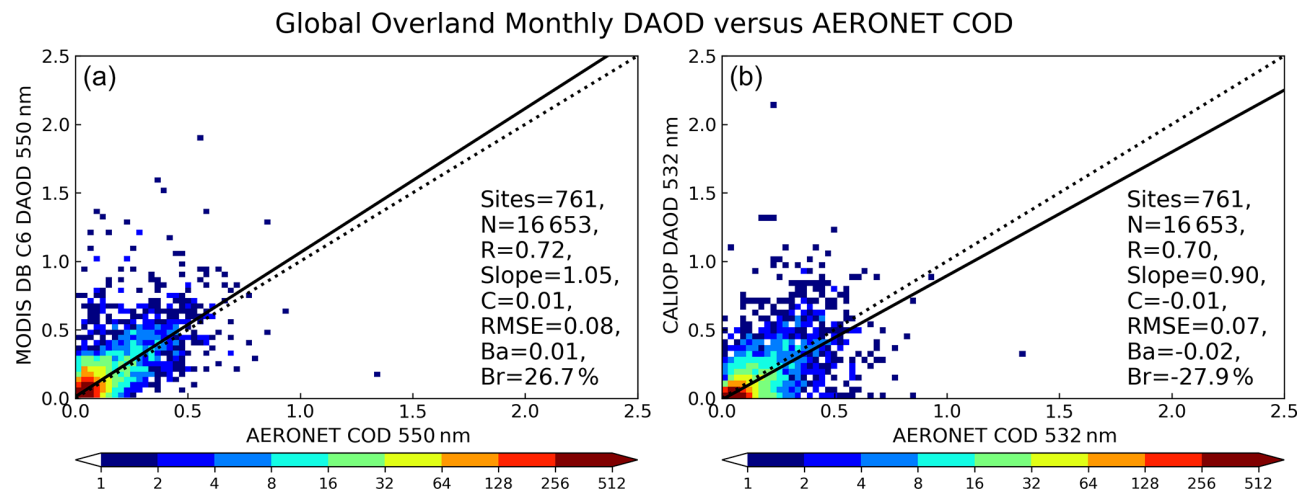

Figure 1. Scatter density histogram comparing monthly (from 2007 to 2019) MODIS DAOD (a) and CALIOP DAOD (b) with monthly coarse-mode $\mathrm{COD}_{\mathrm{SDA}}$ retrieved at $550 \mathrm{~nm}$ for MODIS comparison and at $532 \mathrm{~nm}$ for CALIOP comparison from the level 2 (cloudscreened and quality-assured) spectral deconvolution algorithm (SDA) version 4.1 (O'Neill et al., 2003). The 1-to-1 line and linear regression line are shown by dotted and solid lines, respectively. The number of sites (Sites), matchups $(N)$, correlation $(R)$, slope $(S)$, constant $(C)$, and root mean square error (RMSE) of the linear regression as well as absolute bias $\left(B_{\mathrm{a}}\right)$ and relative Bias $\left(B_{\mathrm{r}}\right)$ are indicated in the lower right of the panel. $B_{\mathrm{a}}, B_{\mathrm{r}}$, and RMSE are defined as $B_{\mathrm{a}}=\overline{\mathrm{DAOD}}_{\mathrm{C} \text { or M }}-\overline{\mathrm{COD}}_{\mathrm{SDA}}, B_{\mathrm{r}}=\overline{\mathrm{DAOD}}_{\mathrm{C} \text { or M}} / \overline{\mathrm{COD}}_{\mathrm{SDA}}-1$, $\mathrm{RMSE}=\sqrt{\frac{\sum_{i}\left(\overline{\mathrm{DAOD}}_{\mathrm{Cor}, i}-\overline{\mathrm{COD}}_{\mathrm{SDA}, i}\right)^{2}}{N}}$.
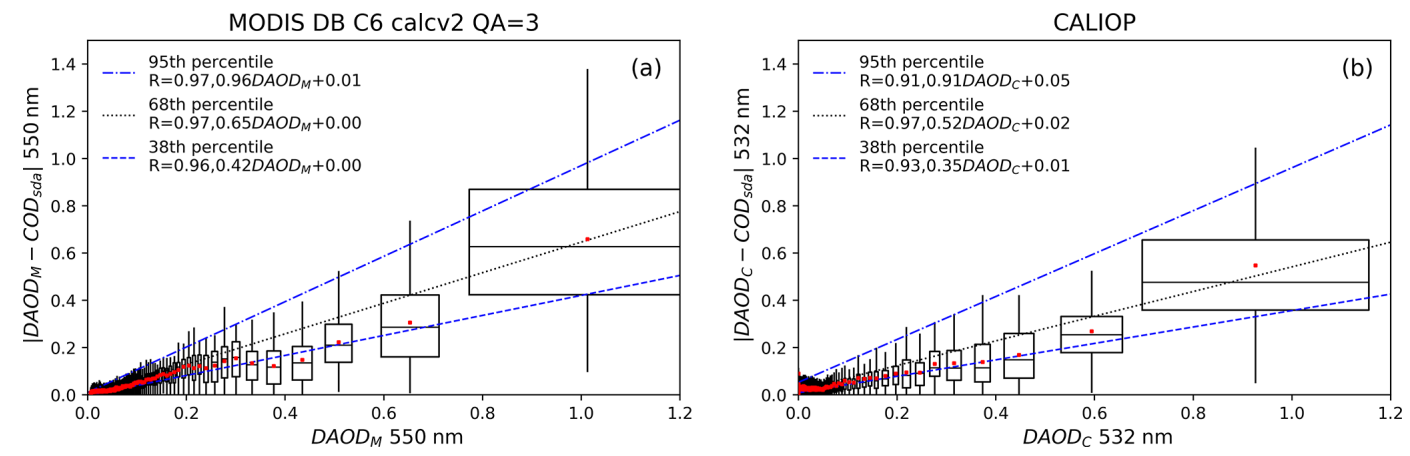

Figure 2. (a) The $x$ axis is the MODIS derived DAOD; the $y$ axis is the absolute MODIS DAOD-AERONET COD difference (without scaling by an geometric air mass factor; AMF). Data are sorted by bins of 100 values (we have 16653 matchups in total; therefore, the last bin has 53 values). The means and standard deviations of the MODIS DAOD $\mathrm{M}$ are the centers and half widths of the boxes in the horizontal. The mean, medians, and lower-to-upper quartile interval of the MODIS-AERONET SDA differences are the red dots, the center, and topbottom intervals of the boxes. The dotted line is the error estimated from the least squares linear fit of the 68th percentiles for each box. Panel (b) is the same except for CALIOP DAOD.

aerosols, as summarized in Table 1. The CALIOPbased method makes use of the fact that the depolarization ratio of dust aerosols is much higher than that of other types of aerosols, primarily because of irregular non-spherical shape and also to a lesser extent because of coarse size of dust particles (Gasteiger et al., 2011; Järvinen et al., 2016). MODIS-based method is largely based on the characteristics of coarse particle size. Over the ocean, DAOD is derived from MODISretrieved TAOD and FMF with a priori characteristic FMF for individual aerosol types. Over land, DAOD is derived using spectral dependence of aerosol extinction (i.e., Ångström exponent) and single-scattering albedo. In other words, MODIS retrieves overland DAOD based on dust size supplemented by absorption characteristics.
Given these retrieval uncertainties and methodological differences, some discrepancies between the two DAOD climatological datasets are expected. In this section, we will compare the two datasets to identify and understand their similarities and differences. Since the mechanisms of dust generation, dust transport, and dust removal processes all have a seasonal cycle (Mbourou et al., 1997; Parrington et al., 1983), we first present and discuss dust spatial distributions for each season in this section. Table 4 summarizes the seasonal and annual mean DAOD and TAOD values averaged over the ocean, land, and the globe (all limited to $60^{\circ} \mathrm{S}-60^{\circ} \mathrm{N}$ ), respectively, based on MODIS and CALIOP dust retrievals from 2007 to 2019. On a multi-year average basis, the global DAOD was found to be 0.055 over the ocean and 0.103 over land based on MODIS, and 0.020 over the ocean and 0.068 over land 

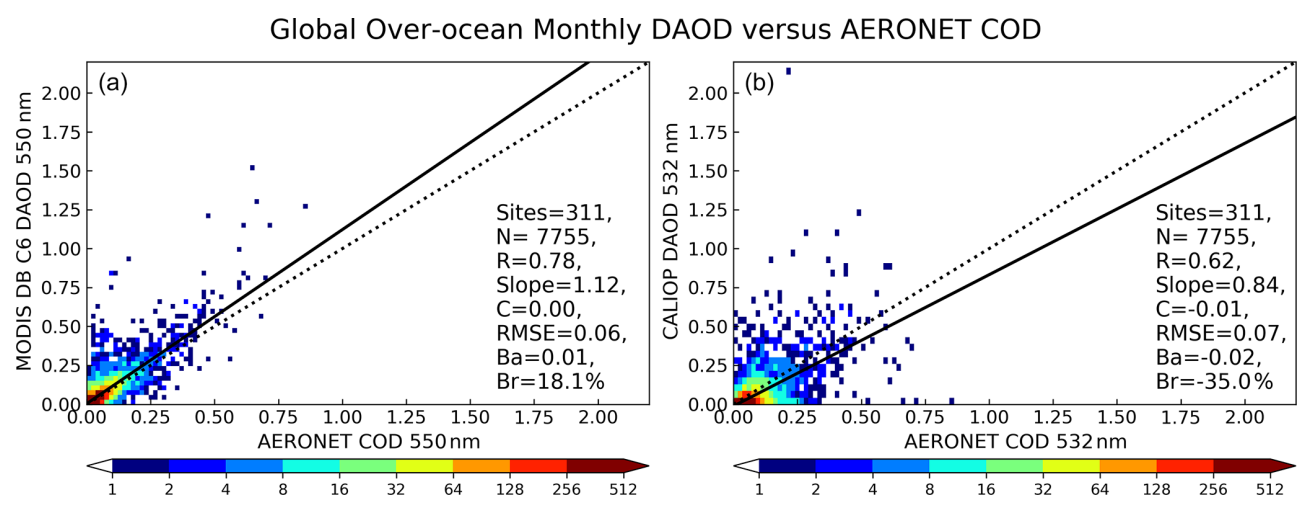

Figure 3. The same as Fig. 1 except for over the ocean.
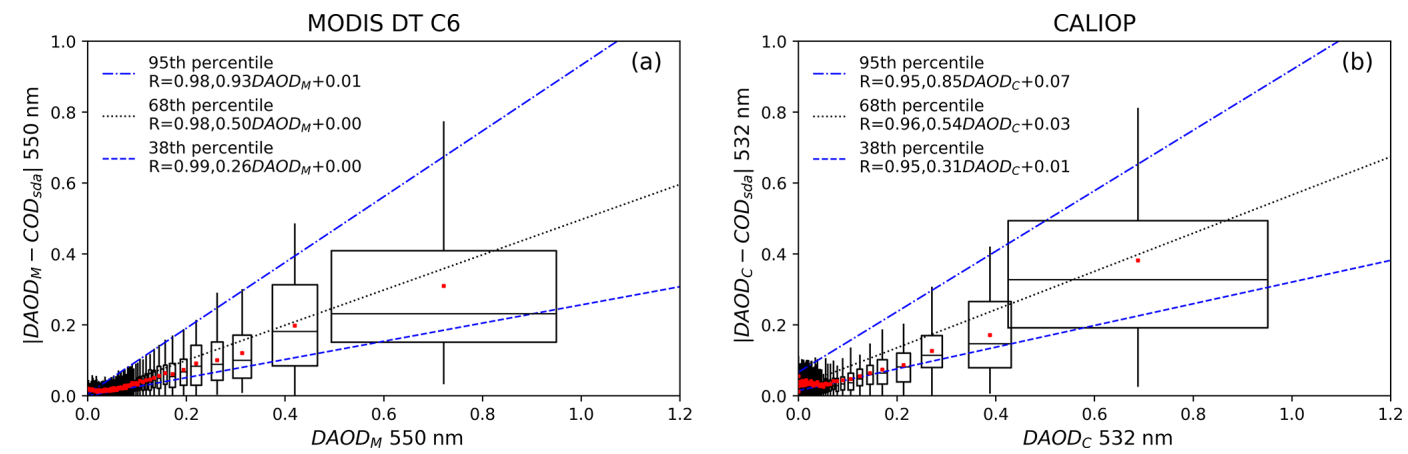

Figure 4. The same as Fig. 2 except for over the ocean.

based on CALIOP. The global annual mean DAOD (TAOD) is $0.032(0.121)$ and $0.067(0.171)$ according to CALIOP and MODIS retrievals, respectively.

As a comparison of two DAOD retrievals in this study, generally, the DAOD from two retrievals differs by a factor of about 3 over the ocean and less than 2 over land, while TAOD differs by a factor of less than 2 over both ocean and land. The ratio of DAOD over land to that over the ocean is about 2 and 3 for MODIS and CALIOP, respectively. For TAOD, the land-to-ocean ratio is about 2 for both products. Overall, the difference in TAOD between two retrievals is less than their difference in DAOD. On a global average, both MODIS and CALIOP-based DAOD peaks in boreal summer (June-July-August). DAOD reaches a minimum in boreal fall (September-October-November) for MODIS but in boreal winter (December-January-February) for CALIOP. The MODIS and CALIOP differences are region dependent, which is discussed as follows.

Figure 5 shows the spatial distribution of seasonal mean DAOD and the percentage of DAOD to the TAOD based on 13-year (2007-2019) CALIOP and MODIS observations. Note that this period is chosen because both datasets are available. Generally, MODIS-based DAOD is larger than CALIOP-based DAOD. As expected, high values are seen from both CALIOP-based and MODIS-based DAOD over the "dust belt" regions extending from the west coast of north Africa to the Middle East, central Asia, and China, where large-scale dust activities occur persistently throughout the year. However, the CALIOP-based DAOD is rather low in some other regions that are known to be dusty in certain seasons, such as the southwestern United States, South America (Patagonian Desert), Australia, and South Africa (i.e., Kalahari Desert). These regions do stand out in MODIS DAOD maps (i.e., the second column in Fig. 5). Then we plot DAOD-to-TAOD ratio based on DAOD and TAOD retrievals from two sensors (the last two columns in Fig. 5). These regions indeed show up in the DAOD-to-TAOD ratio plot based on both sensors (i.e., the last two columns in Fig. 5). This means that in those regions both sensor-specific methodologies are able to distinguish dust aerosol from sensor-detected total aerosol to some extent so that the DAOD-to-TAOD ratio stands out in those regions for both sensors.

A close examination of Fig. 5 revealed a land-to-ocean discontinuity in MODIS-based DAOD along the west African coastlines, especially between $30^{\circ} \mathrm{S}$ and $0^{\circ} \mathrm{N}$ in the summer and fall seasons. This discontinuity could have been caused by several factors. First, we used the MODIS DB and DT products to derive DAOD over land and ocean, respectively. It is known the DB and DT algorithms are based on different methods and implemented by different groups, which inevitably leads to significant differences between the two and contributes to the discontinuity. This discontinuity has been 
Table 3. Statistical parameters and absolute error by continents using the method indicated in Fig. 1. Sites is the number of AERONET sites involved; $N$ is the number of MODIS, CALIOP and AERONET matchups. $R$ is correlation coefficient; $C$ is the intercept of the linear fit; $K$ is the slope of the linear fit; RMSE is root mean square error of the linear fit; $B_{\mathrm{a}}$ is the absolute bias; $B_{\mathrm{r}}$ is the relative bias. For cells with two rows of values, the upper row is for MODIS, the lower row is for CALIOP.

\begin{tabular}{lcrrrrrrrl}
\hline Region & Sites & $N$ & $R$ & $C$ & $K$ & RMSE & $B_{\mathrm{a}}$ & $B_{\mathrm{r}}(\%)$ & Absolute error \\
\hline Global & 761 & 16653 & 0.72 & 0.01 & 1.05 & 0.08 & 0.01 & 26.7 & $0.65 \times \mathrm{DAOD}_{\mathrm{M}}$ \\
& & & 0.70 & -0.01 & 0.90 & 0.07 & -0.02 & -27.9 & $0.52 \times \mathrm{DAOD}_{\mathrm{C}}+0.02$ \\
\hline Africa & \multirow{2}{*}{44} & 706 & 0.79 & 0.04 & 0.72 & 0.10 & 0.01 & 4.5 & $0.37 \times \mathrm{DAOD}_{\mathrm{M}}+0.01$ \\
& & & 0.72 & 0.01 & 0.75 & 0.12 & -0.02 & -19.8 & $0.51 \times \mathrm{DAOD}_{\mathrm{C}}+0.02$ \\
\hline Asia & \multirow{2}{*}{143} & 2507 & 0.64 & 0.04 & 0.88 & 0.10 & 0.03 & 34.2 & $0.61 \times \mathrm{DAOD}_{\mathrm{M}}$ \\
& & & 0.57 & 0.00 & 0.84 & 0.11 & -0.01 & -11.0 & $0.66 \times \mathrm{DAOD}_{\mathrm{C}}+0.01$ \\
\hline Europe & 156 & \multirow{2}{*}{4359} & 0.27 & 0.03 & 0.55 & 0.05 & 0.01 & 18.2 & $0.70 \times \mathrm{DAOD}_{\mathrm{M}}$ \\
& & & 0.35 & 0.00 & 0.53 & 0.04 & -0.02 & -48.6 & $0.47 \times \mathrm{DAOD}_{\mathrm{C}}+0.02$ \\
\hline Americas & \multirow{2}{*}{319} & \multirow{2}{*}{6656} & 0.29 & 0.02 & 0.54 & 0.04 & 0.01 & 25.5 & $0.77 \times \mathrm{DAOD}_{\mathrm{M}}$ \\
& & & 0.33 & 0.00 & 0.31 & 0.03 & -0.02 & -55.8 & $0.26 \times \mathrm{DAOD}_{\mathrm{C}}+0.02$ \\
\hline Australia & \multirow{2}{*}{12} & 507 & 0.51 & 0.0 & 0.57 & 0.03 & -0.02 & -43.9 & $0.37 \times \mathrm{DAOD}_{\mathrm{M}}+0.02$ \\
& & & 0.28 & 0.0 & 0.32 & 0.04 & -0.02 & -59.3 & $0.34 \times \mathrm{DAOD}_{\mathrm{C}}+0.03$ \\
\hline
\end{tabular}

Table 4. Global $\left(60^{\circ} \mathrm{S}-60^{\circ} \mathrm{N}\right)$ seasonal mean DAOD and TAOD based on MODIS and CALIOP (2007-2019) dust retrievals. Since Earth is a sphere, grid-cell surface area decreases toward the poles. We weight each grid-cell surface area into ocean, land, and global DAOD averages.

\begin{tabular}{llrr|rr|rr|r|r|r|r}
\hline & & \multicolumn{2}{c}{ MAM } & \multicolumn{2}{c|}{ JJA } & \multicolumn{2}{c|}{ SON } & \multicolumn{2}{c}{ DJF } & Annual \\
\cline { 3 - 11 } & & DAOD & TAOD & DAOD & TAOD & DAOD & TAOD & DAOD & TAOD & DAOD & TAOD \\
\hline \multirow{2}{*}{ MODIS } & Ocean & 0.057 & 0.151 & 0.062 & 0.153 & 0.047 & 0.143 & 0.052 & 0.144 & 0.055 & 0.148 \\
& Land & 0.131 & 0.283 & 0.119 & 0.270 & 0.079 & 0.206 & 0.085 & 0.217 & 0.103 & 0.244 \\
& Global & 0.075 & 0.183 & 0.077 & 0.183 & 0.055 & 0.159 & 0.059 & 0.160 & 0.067 & 0.171 \\
& Land/ocean & 2.27 & 1.87 & 1.90 & 1.77 & 1.67 & 1.44 & 1.64 & 1.51 & 1.89 & 1.65 \\
\hline \multirow{2}{*}{ CALIOP } & Ocean & 0.022 & 0.098 & 0.025 & 0.104 & 0.015 & 0.092 & 0.016 & 0.090 & 0.020 & 0.096 \\
& Land & 0.086 & 0.196 & 0.086 & 0.228 & 0.051 & 0.186 & 0.047 & 0.157 & 0.068 & 0.192 \\
& Global & 0.039 & 0.124 & 0.041 & 0.137 & 0.025 & 0.117 & 0.024 & 0.107 & 0.032 & 0.121 \\
& Land/ocean & 3.90 & 1.99 & 3.45 & 2.20 & 3.40 & 2.03 & 2.87 & 1.74 & 3.45 & 2.00 \\
\hline
\end{tabular}

pointed out in previous studies (e.g., H. Yu et al., 2021). Second, MODIS AOD retrievals are susceptible to cloud contaminations. The southeast Atlantic region has one of largest stratocumulus decks, whose cloud amount peaks in summer and fall seasons (Klein and Hartmann, 1993). Therefore, cloud contamination in MODIS DT retrievals over the ocean leads to overestimation of AOD and underestimation of FMF and hence overestimation of DAOD (Yu et al., 2020). In addition, as explained in Sect. 3, we used different methods to derive the DAOD from the TAOD over land and ocean, which could also contribute to the problem. This land-to-ocean discontinuity is an important limitation of the current method. To mitigate this problem, substantial efforts are needed to improve the MODIS DT AOD and FMF retrievals and better understand the difference between DT and DB algorithm, which is beyond the scope of this study.
The climatological dust product shown in Fig. 5 is a measure of the average dust loading over a geographical domain and time interval. It contains information of both the intensity and frequency of dust activities. The seasonal conditionally sampled DAOD shown in the first column of Fig. 6 eliminates the impacts from dust frequency by excluding dust-free cases in the average. It is mainly related to the intensity of observed dust events. Therefore, the comparison between climatological and conditionally sampled DAOD sheds a light on the frequency and intensity of dust events detected by CALIOP. Therefore, we further compare the seasonal climatological DAOD and conditional DAOD product. The second column in Fig. 6 shows the seasonal climatological DAOD. The third column in Fig. 6 shows the relative difference between conditionally sampled DAOD and climatological DAOD with respect to the climatological DAOD. In 

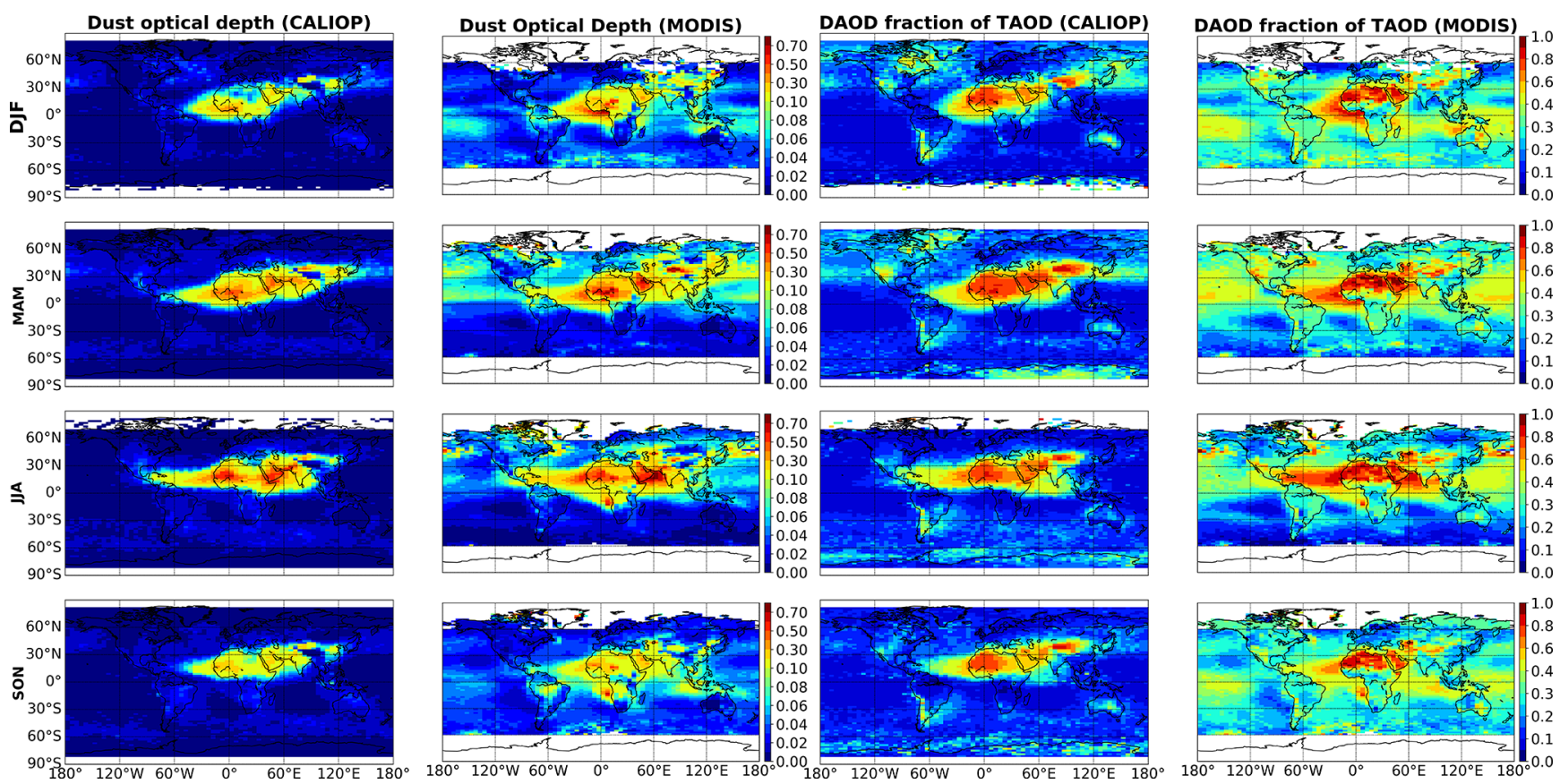

Figure 5. Spatial distribution of the seasonal mean CALIOP-based DAOD, MODIS-based DAOD, and the fraction of DAOD with respect to the TAOD based on CALIOP and MODIS, respectively, for the globe at a $5^{\circ}$ longitude $\times 2^{\circ}$ latitude resolution based on 13-year (2007-2019) CALIOP measurements. DJF: December of the previous year-January-February; MAM: March-April-May; JJA: June-July-August; SON: September-October-November.

"dust belt" regions, especially in the Sahara and Middle East where dust activities are persistent, climatological DAOD is very close to conditional DAOD. In Australia, southwestern United States, South America, and South Africa, however, the conditional DAOD (column 1 in Fig. 6) and the difference (column 3 in Fig. 6) are relatively high. This suggests that dust activities in those regions are highly episodic and/or occur in relatively small scales. The difference also is very large in open oceans, suggesting that dust aerosols are present at a very low frequency.

Having analyzed the conditionally sampled DAOD from CALIOP, we now return to climatological DAOD and comparison between CALIOP and MODIS. Hereafter, all AOD values are climatological without otherwise explicit statement. Figure 7 shows the difference in seasonal mean TAOD, DAOD, and the percentage of DAOD in TAOD between MODIS retrievals and CALIOP retrievals. We first focus on the "dust belt" and its ocean out-flow regions extending from the northeastern Atlantic, north Africa to the Middle East, central Asia, China, and northwestern Pacific. We note that in Fig. 7 CALIOP-based TAOD and DAOD are generally smaller than MODIS-based ones over north Africa and the Saharan dust outflow region over the tropical Atlantic Ocean. One of the reasons for this large discrepancy is the selection of LR in CALIOP aerosol retrieval in these regions. CALIOP V4 products retrieve dust extinction coefficients with two steps. First, apply a globally uniform LR of $44 \mathrm{sr}$ for the identified dust aerosol layers to retrieve backscatter coefficients. Second, use the same LR of $44 \mathrm{sr}$ value to convert backscatter coefficients to extinction coefficients. Amiridis et al. (2013) showed that in the second step applying an LR of $58 \mathrm{sr}$ to CALIOP dust backscatter coefficients in north Africa improves the resulting aerosol extinction in terms of optical depth comparison with synchronous and collocated AERONET and MODIS measurements. Similarly, over the Sahara and the tropical Atlantic Ocean (see Fig. 8a and d), we apply an LR of $58 \mathrm{sr}$ to the derived backscatter coefficient of the dust component to get extinction coefficient of dust component. The resulting DAOD for an LR of 58 sr shows an improvement in comparison with MODIS DAOD relative to an LR of $44 \mathrm{sr}$ (Fig. 9a and d). Therefore, the choose of LR can largely explain the difference between MODIS and CALIOP DAOD over north Africa and the tropical Atlantic Ocean. For other regions, typical values of LR of desert dust aerosols vary between 35 and 55 sr, which is basically covered by the range of $44 \pm 9 \mathrm{sr}$ used in this study. The DAOD uncertainty induced by $\pm 9 \mathrm{sr}$ is estimated to be around $20 \%$ as shown in the shaded area in Fig. 9.

In the Middle East (the region indicated by Fig. 8b), the second column in Fig. 7 shows that MODIS DAOD is generally larger than CALIOP DAOD in the Arabian Peninsula, while it is opposite in India.

In the Arabian Sea (the region indicated by Fig. 8h), comparing column 2 and column 4 in Fig. 7, we could see that 

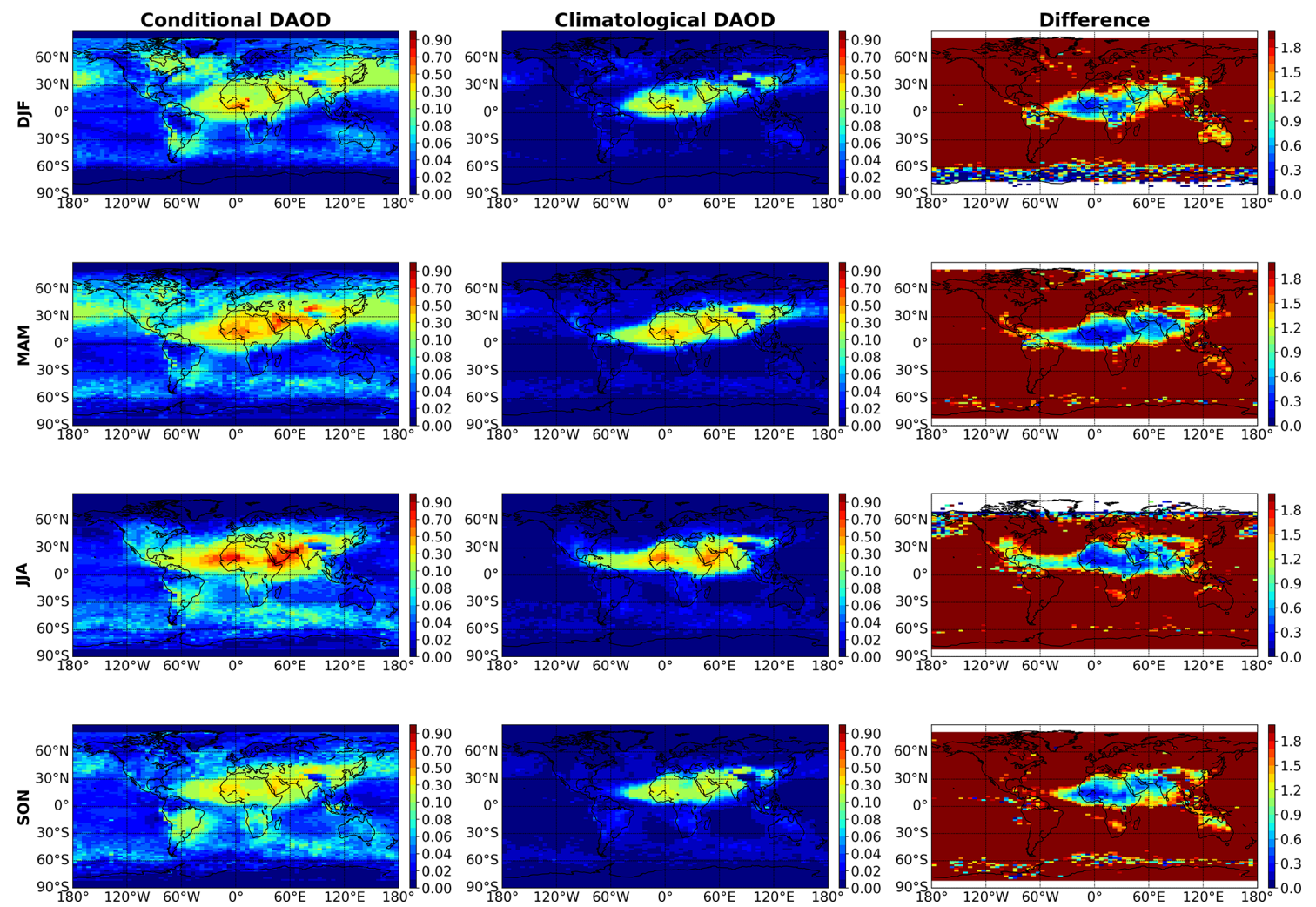

Figure 6. Conditional DAOD (the first column) and climatological DAOD (the second column) based on CALIOP dust retrieval from 2007 to 2019. The third column shows the relative difference between conditionally sampled DAOD and climatological DAOD with respect to the climatological DAOD expressed in fraction.
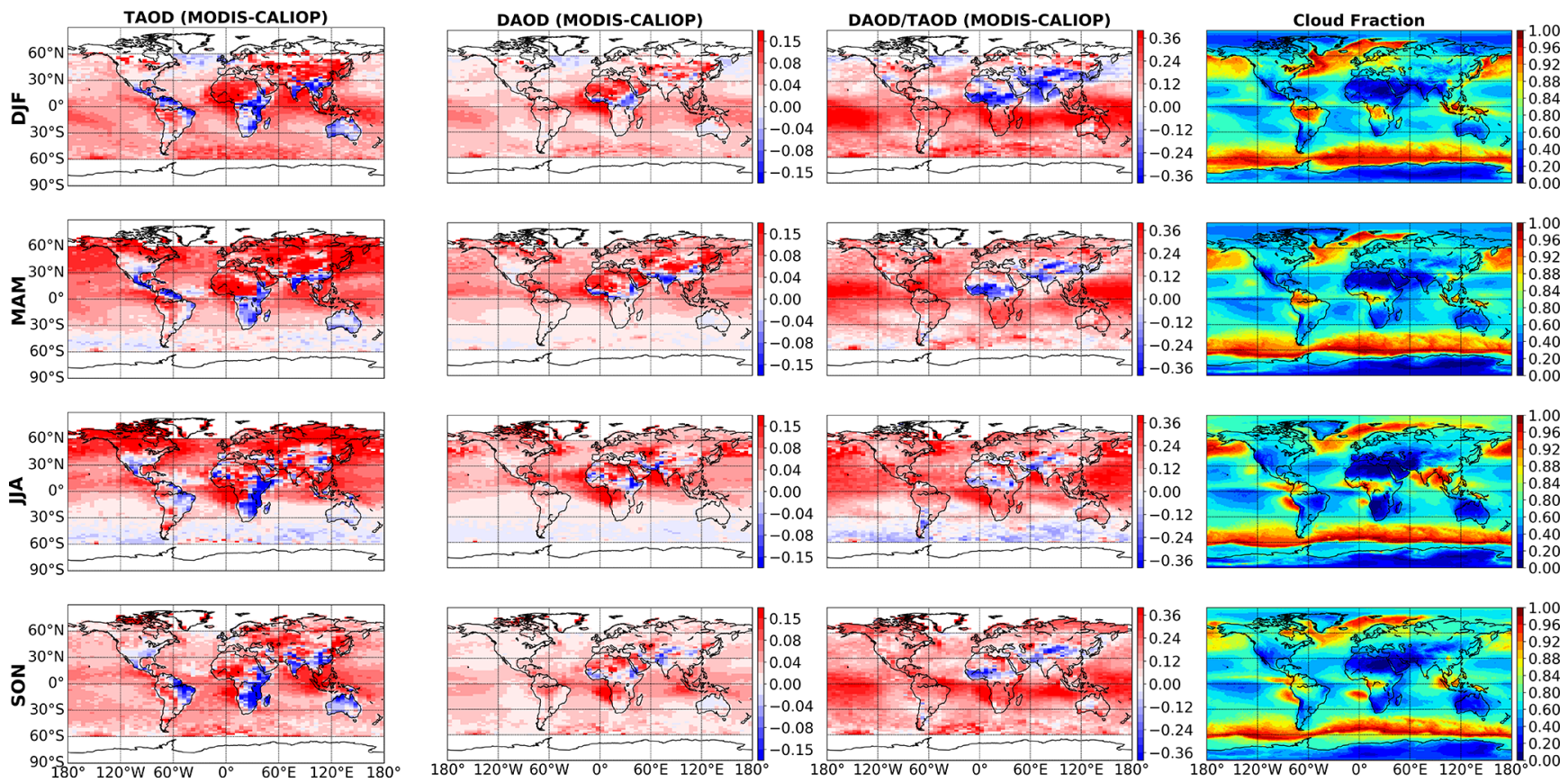

Figure 7. The difference between MODIS and CALIOP for seasonal mean TAOD (the first column), DAOD (the second column), and the fraction of DAOD in TAOD (the third column) on a basis of the 13-year (2007-2019) average. The fourth column is the seasonal mean cloud fraction from MODIS L3 product. 


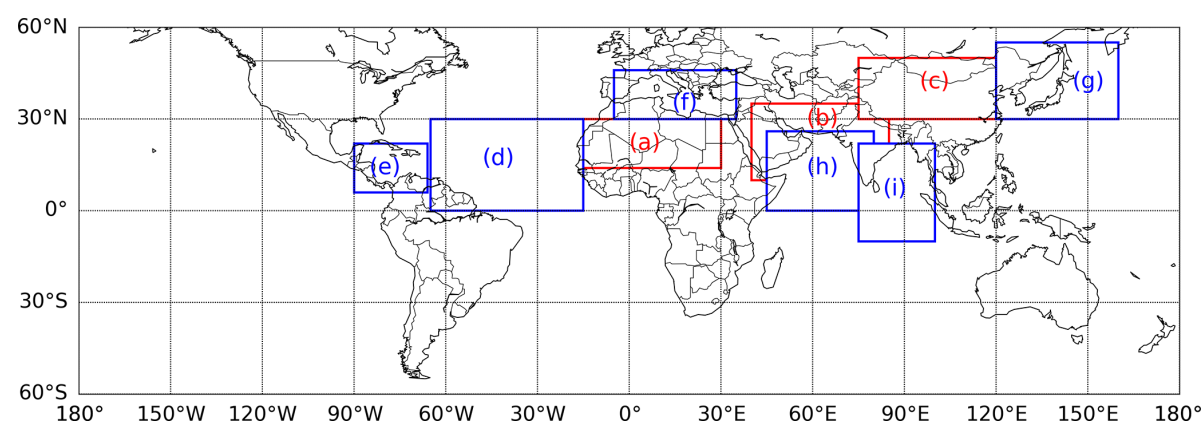

Figure 8. Major dust-laden regions including three dust source regions on land (a-c) and six outflow regions over the ocean (e-i). (a) Sahara $\left(14-30^{\circ} \mathrm{N}, 15^{\circ} \mathrm{W}-30^{\circ} \mathrm{E}\right)$, (b) Middle East $\left(10-35^{\circ} \mathrm{N}, 40-85^{\circ} \mathrm{E}\right)$, (c) eastern Asia $\left(30-50^{\circ} \mathrm{N}, 75-130^{\circ} \mathrm{E}\right)$, (d) the tropical Atlantic Ocean TAT $\left(0-30^{\circ} \mathrm{N}, 15-60^{\circ} \mathrm{W}\right)$, (e) the Caribbean Sea - CRB $\left(6-22^{\circ} \mathrm{N}, 60-90^{\circ} \mathrm{W}\right)$, (f) the Mediterranean Sea $-\mathrm{MED}\left(30-46^{\circ} \mathrm{N}, 5^{\circ} \mathrm{W}-35^{\circ} \mathrm{E}\right)$, (g) the northwest Pacific Ocean - NWP $\left(30-55^{\circ} \mathrm{N}, 120-160^{\circ} \mathrm{E}\right)$, (h) the Arabian Sea - ARB $\left(0-26^{\circ} \mathrm{N}, 45-80^{\circ} \mathrm{E}\right)$, and (i) the tropical Indian Ocean and the Bay of Bengal - IND $\left(10^{\circ} \mathrm{S}-22^{\circ} \mathrm{N}, 75-100^{\circ} \mathrm{E}\right)$. Note that we only consider grids over land for the three dust source regions and grids over the ocean for the six dust outflow regions.
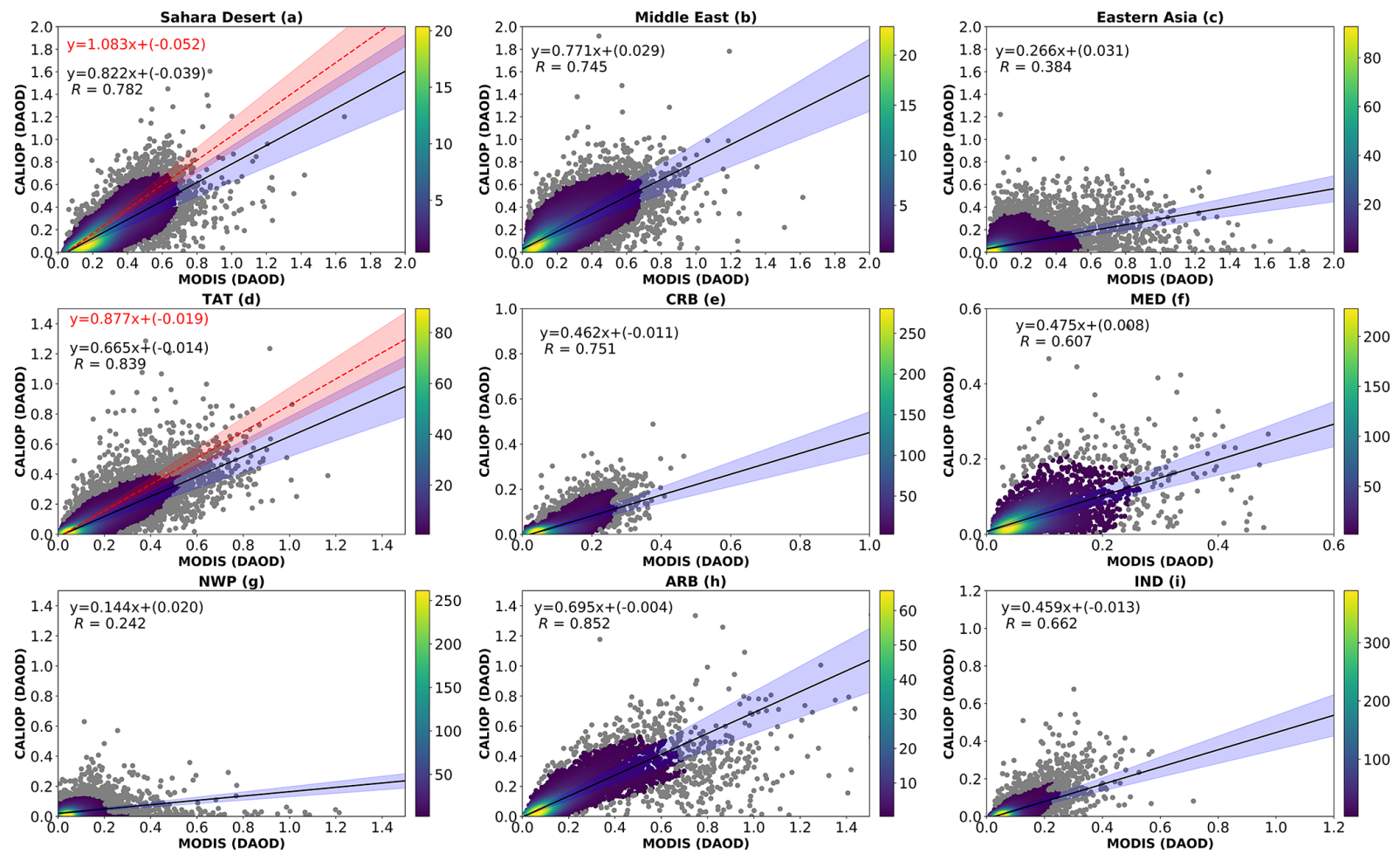

Figure 9. Comparison of CALIOP DAOD against MODIS DAOD over dust-laden regions indicated in Fig. 8. Color represents the probability density using Gaussian kernel density estimation. Gray points represent data points within the lowest $5 \%$ of data density. Those gray points are excluded in the linear regression analysis. The black line and blue shadow are the linear regression for LR $=44 \pm 9$ sr; the red line and red shadow in panels (a) and (d) represent the linear regression for LR $=58 \pm 8$ sr. The red text in panels (a) and (d) is the linear fit based on $\mathrm{LR}=58 \mathrm{sr}$. The black text in each panel is the linear fit based on LR $=44 \mathrm{sr}$. $R$ is Pearson's linear correlation coefficient between MODIS and CALIOP DAOD.

MODIS DAOD is significantly larger than CALIOP DAOD during JJA, during which cloud fraction is very high in the region. MODIS aerosol retrieval is more susceptible to cloud contamination. Specifically, the cloud contamination can lead to an overestimation of TAOD but underestimation of FMF. Although the MODIS retrieval algorithm neither as- sume coarse particles are exclusively from dust aerosols nor assume dust particles are all coarse particles (Yu et al., 2020), coarse-mode aerosols are primarily dust. Thus, the overestimation of TAOD and underestimation of FMF will lead to an overestimation in DAOD. 
Over eastern Asia and the Asian dust outflow region (northwestern Pacific Ocean; NWP), CALIOP-based DAOD is generally smaller than MODIS-based DAOD. There could be several reasons for this. First, this region is a major outflow region of Asian pollution (Yu et al., 2020). It is possible that the internal mixing of dust aerosols with industrial pollution in this region changes the dust morphology making it less non-spherical (Li and Shao, 2009; Huang et al., 2020) but larger in size, which leads to smaller depolarization ratio and smaller fine-mode fraction. As a result, CALIOP shape-based DAOD derivation method could not capture the dust particles contained in the mixture, while those dust particles can be captured by MODIS size-based method. Another potential reason could be associated with that dust plumes in this region are vertically dispersed (Yu et al., 2010; Su and Toon, 2011). These tenuous dust layers are likely to go undetected by CALIOP because of its relatively low sensitivity. However, MODIS retrieves aerosol from the columnal integrated reflectance which is not dependent on the vertical distribution of aerosol. The difference may also be caused by uncertainties in MODIS aerosol retrievals. The west Pacific Ocean is cloudy almost all year long (see the last column in Fig. 7), which makes MODIS aerosol retrievals bias high due to its more susceptibility to cloud contamination. An exception occurs during winter when cloud fraction is large in NWP. The MODIS-based DAOD is smaller than CALIOP-based DAOD, even though MODIS TAOD is larger than CALIOP TAOD. Similarly, over the southeastern Atlantic Ocean, CALIOP-based DAOD is also generally smaller than MODIS-based DAOD. On one hand, cloud contamination may have biased the MODIS dust retrieval high. On the other hand, CALIOP clear-sky sampling is not large enough to capture some dust events in this region.

We further compare DAOD (Fig. 9) and TAOD (Fig. S7 in the Supplement) retrievals from CALIOP and MODIS over major dust-laden regions (as shown in Fig. 8), including three source regions on land (i.e., the Sahara, Middle East, and eastern Asia) and six oceanic outflow regions (i.e., the Tropical Atlantic Ocean - TAT, the Caribbean Basin - CRB, the Mediterranean Sea - MED, the Northwest Pacific Ocean NWP, the Arabian Sea - ARB, as well as the tropical Indian Ocean and the Bay of Bengal - IND). Each data point in the scatter plot represents a monthly mean DAOD (or TAOD) in a $2^{\circ} \times 5^{\circ}$ grid. The density of data is represented by different color. To avoid our analysis being biased by some extreme and rare cases, we exclude those data points within the lowest $5 \%$ of data density (gray points in Figs. 9 and S7). Overall, the DAOD from the two instruments correlate well $(R>0.75)$ and on average CALIOP-based DAOD is $18 \%, 34 \%, 54 \%$ and $31 \%$ lower than MODIS-based DAOD over the Sahara (Fig. 9a), TAT (Fig. 9d), CRB (Fig. 9e), and ARB (Fig. 9h) regions, respectively. Applying LR of $58 \mathrm{sr}$ to Saharan dust reduces the difference from $18 \%$ to $8 \%$ over the Sahara and from $34 \%$ to $12 \%$ over TAT. Over the Sahara, the good agreement in DAOD between the two sensors (bias of $8 \%$ and $R=0.78$ ) suggests that over the Sahara, dust particles can be adequately characterized by both irregular non-spherical shape and coarse size. As a result, both CALIOP- and MODIS-based methods are able to detect and separate the dust from other types of aerosols. In TAT and ARB regions, two instruments correlate well $(R>0.8)$ in both DAOD and TAOD. For TAOD, CALIOP is smaller than MODIS by $2 \%$ in TAT and larger than MODIS by $15 \%$ in ARB. Differences in DAOD are larger, with CALIOP DAOD lower than the MODIS DAOD by $12 \%$ and $31 \%$ in TAT and ARB, respectively. This suggests that the differences in DAOD from the two instruments mainly resulted from differences in the dust separation method. In East Asia and NWP, on contrast, both TAOD and DAOD show poor correlation between the two methods (Fig. 9c, g, S7c, and g). As discussed earlier, the poor correlation between the two methods has contributions from many factors. For example, the total TAOD retrievals from MODIS are subject to larger uncertainties due to cloud contamination, or the DAOD retrieval from CALIOP may miss spherical dust particles that are coated by large combustion emissions from East Asia.

\subsection{Comparison between CALIOP and MODIS DAOD seasonality}

Figure 10 compares annual cycle of MODIS and CALIOP DAOD based on the 13-year (2007-2019) average over the nine dust-laden regions. Each data point represents domainaveraged 13-year mean DAOD for a month, while the error bar indicates $\pm 1 \sigma$ ( 1 standard deviation of DAOD). The seasonal cycles of dust activities and dust transport are consistent with results in literature. For example, Prospero et al. (2002) shows that dust activity peaks in May-July in north Africa and the Middle East, while it peaks in spring in China. These seasonal cycles are consistent with our results shown in the first row of Fig. 10. Yu et al. (2015a) shows that DAOD peaks in June-July-August in La Parguera, which is consistent with the seasonal cycle in CRB in this study. Generally, CALIOP and MODIS show very similar seasonality over those dust-laden regions. DAOD peaks in summer June-July-August (JJA) over the Sahara, Middle East, TAT, CRB, ARB, and IND, but in spring MarchApril-May (MAM) over eastern Asia, MED, and NWP. Over NWP, the seasonal cycle of MODIS DAOD is somewhat different from that of CALIOP DAOD. While CALIOP DAOD peaks in spring, MODIS DAOD shows a peak in late spring or even summer months for some years. This could have resulted from cloud contamination in MODIS retrievals due to the large cloud fraction in summer (Yu et al., 2020).

Compared to the MODIS dust retrieval, CALIOP has a unique capability of detecting dust aerosol vertical distribution. Figure 11 shows seasonal mean dust extinction vertical profile from CALIOP for the nine dust-laden regions. The values on each plot represent the seasonal mean DAOD. Both DAOD and dust vertical structure have a seasonal de- 

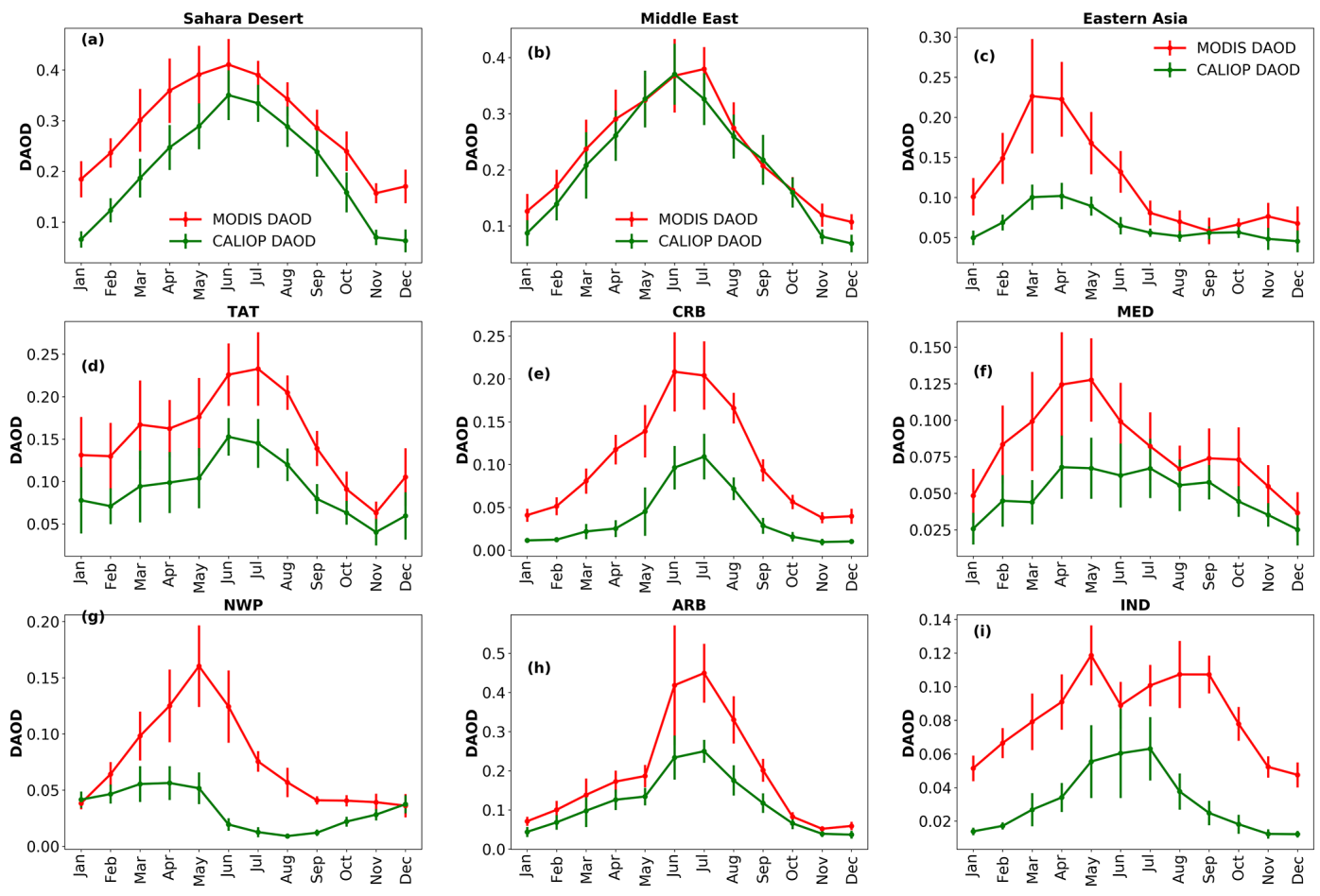

Figure 10. Monthly variation of DAOD from CALIOP (green) and MODIS (red) for major dust-laden regions indicated in Fig. 4. The vertical line represents $\pm 1 \sigma$ (standard deviation) over the 13-year period.

pendence. In the Sahara (Fig. 11a), Middle East (Fig. 11b), and their dust outflow regions the tropical Atlantic (Fig. 11d) and the Arabian Sea (Fig. 11h), summertime dust aerosol has the highest DAOD and reaches to the highest altitude extending from surface up to $6 \mathrm{~km}$ in altitude.

The analysis above has been performed over the broad dust-laden regions. Here, we focus on MODIS and CALIOP comparison in major potential source areas (PSAs) for dust in north Africa, namely NAF-1 to NAF-6, as illustrated in Fig. 12 (adapted from Fig. 1 in Formenti et al., 2011). Among all dust source regions around the globe, the Sahara and its margins in north Africa are the largest dust emitter. Within this region, prominent dust sources are often associated with topographical lows and foothills of mountains (Prospero et al., 2002). Seasonal variations of DAOD in the six PSAs are shown in Fig. 13. Two $B$ values are shown in the upper left of each panel in Fig. 13, where $B$ is defined as the average of CALIOP DAOD/MODIS DAOD ratios of all data pairs. $B=1,>1$, and $<1$ indicates no bias, high bias, and low bias. They are calculated based on CALIOP DAOD using dust LR of 44 and $58 \mathrm{sr}$ respectively. The CALIOP DAOD derived using larger LR (58 sr) achieve a better agreement ( $B$ values are closer to 1 ) with MODIS DAOD. Striking CALIOP and MODIS differences in DAOD exist in NAF-5, where the mean bias $(B)$ deviates far from 1. NAF-5 (14$20^{\circ} \mathrm{N}, 15-20^{\circ} \mathrm{E}$ ) is located in the Bodélé Depression, western Chad. This region is reported as the most intense dust source in the world (Prospero et al., 2002), and dust activity in the region occurs with a high frequency during all seasons except fall (Mbourou et al., 1997). However, CALIOP DAODs are much smaller than MODIS retrievals in this region. In terms of dust seasonality (Fig. 13), the MODIS DAOD indicates intense dust aerosol loading all year long with a lower DAOD in the fall, while CALIOP shows a more distinct seasonality with the highest DAOD of about 0.3 in May-July and the lowest DAOD of $<0.1$ in winter. Over other PSAs in north Africa, MODIS and CALIOP DAOD show similar seasonality with $B$ closing to 1 (Fig. 13).

In summary, MODIS and CALIOP DAOD show largest differences under the following conditions: (1) highly cloudy oceanic regions and (2) dust-pollution internal mixtures with high relative humidity. Their differences can be explained as follows.

Over cloudy ocean, effective cloud screening is critical to the quality of aerosol retrievals. As an active sensor, CALIOP is more reliable in discriminating clouds and aerosols than passive imager MODIS. In addition, active sensor is able to avoid impact from cloud-side scattering. Therefore, MODIS is subject to more cloud contamination than CALIOP. Large cloud contamination in MODIS results in overestimation in TAOD and underestimation in FMF, introducing a high bias in DAOD over cloudy ocean regions (e.g., NWP).

Pure dust particles are hydrophobic and will not absorb water vapor. However, for dust aerosols coated by other types of aerosols (such as the deliquescent dust-nitrate $\mathrm{Ca}\left(\mathrm{NO}_{3}\right)_{2}$ ) and saline mineral dust particles emitted from saline topsoil 

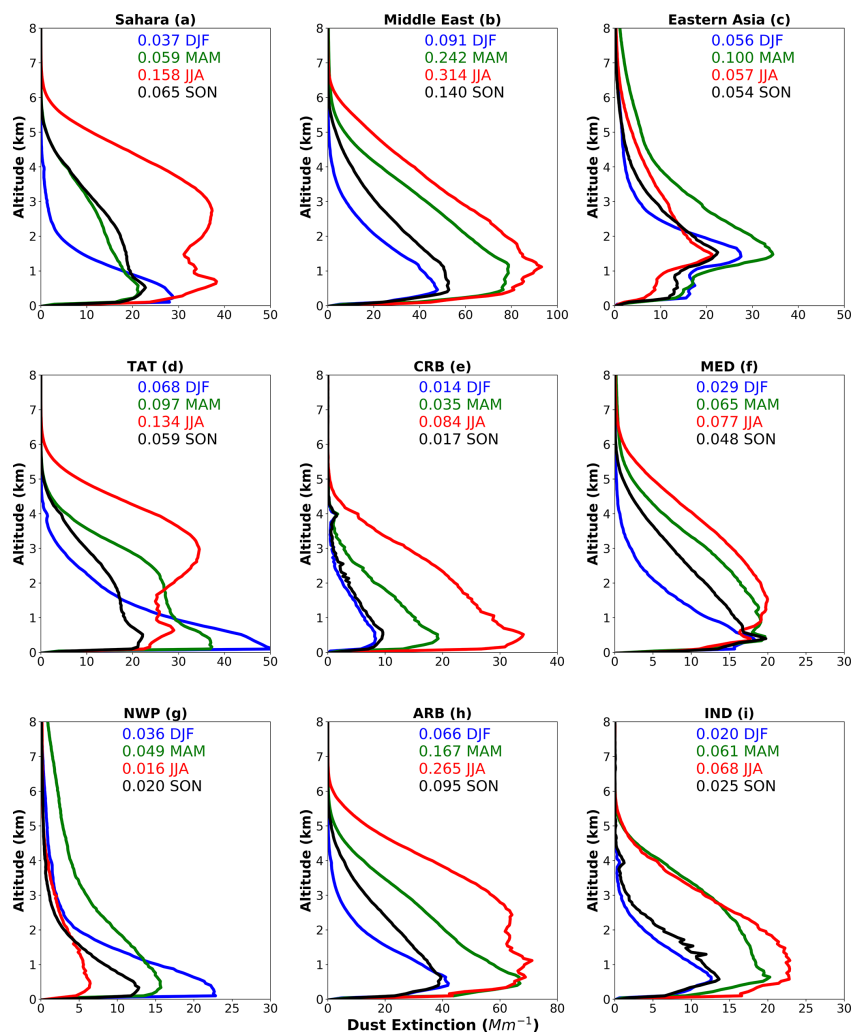

Figure 11. Vertical profiles of seasonal mean dust extinction coefficient $\left(\mathrm{M} \mathrm{m}^{-1}\right)$ in nine dust-laden regions indicated in Fig. 4. Different colors represent different seasons. The numbers on each plot are the seasonal mean DAOD for the region.

in arid and semiarid areas (Tang et al., 2019), those types of dust particles will take up water vapor and grow to be larger in size and more spherical in shape (Wu et al., 2020c). This phenomenon is most prominent for dust aerosols in polluted region (e.g., EAS) as well as with relatively high relative humidity. While such coarse spherical dust particles will not be accounted for as dust in the CALIOP shape-based method, they are categorized as dust in the MODIS sizebased method.

\subsection{DAOD interannual variation from CALIOP and MODIS observations}

In this section, we examine the interannual variation of DAOD captured by two sensors over several major dust source and outflow regions. Figure 14 shows a global map of DAOD trend derived based on the 13-year (2007-2019) time series of annual mean DAOD from CALIOP and MODIS. DAOD trends are calculated for each $2^{\circ} \times 5^{\circ}$ grid. The red color indicates positive trend and blue negative trend. Regions where the trend is statistically significant $(p<0.05)$ are marked with a "+" symbol. The similar trend map for total aerosol optical depth is shown in Fig. S8. Overall, the DAOD global pattern of interannual trend is similar to
TAOD in major dust-laden regions. For example, over the Sahara and tropical Atlantic Ocean region, both CALIOP and MODIS do not show a statistically significant trend in DAOD and TAOD. In East Asia and the northwest Pacific Ocean, both sensors show a negative trend in DAOD and TAOD.

Figure 15 displays interannual variability of annual-mean DAOD for the major dust-laden regions as defined in Fig. 8. Seasonal and annual DAOD trends in the nine regions are listed in Table 5. Both MODIS and CALIOP show a clear DAOD trend in certain seasons over the eastern Asia, ARB, and NWP regions. In eastern Asia, MODIS and CALIOP show a consistent DAOD decreasing trend at a rate of $-1.7 \% \mathrm{yr}^{-1}$ annually. The two sensors show a DAOD decreasing tend of $-3.5 \% \mathrm{yr}^{-1}$ and $-2.5 \% \mathrm{yr}^{-1}$, respectively, in eastern Asia during spring and show a consistent trend of DAOD in ARB during the fall, though with a factor of 2 difference in magnitude. In NWP, both MODIS- and CALIOPbased DAOD shows a decreasing trend of $-1.7 \% \mathrm{yr}^{-1}$ and $-1.6 \% \mathrm{yr}^{-1}$, respectively. The annual DAOD decreasing trend in NWP is mainly attributed to the DAOD decline in spring at a rate of $-2.3 \% \mathrm{yr}^{-1}$ and $-3.0 \% \mathrm{yr}^{-1}$ for MODIS and CALIOP, respectively. For comparison, Shimizu et al. (2017) detect the decreasing DAOD trends of $-4.3 \% \mathrm{yr}^{-1}$ in spring and $-2.5 \% \mathrm{yr}^{-1}$ on annual mean basis from the Asian Dust Network (AD-Net) lidar observations over Japan (2007-2016). These trends are greater than our results based on MODIS and CALIOP data records.

Dust over NWP comes mainly from East Asian dust sources. The broad East Asian region (ESA, defined in Fig. 12) shows statistically significant DAOD decreasing trends (Fig. 15c), which is consistent with the DAOD decreasing trend in NWP. It is also imperative to further examine which of six major PSAs in East Asia (ESA-1 to ESA6 in Fig. 12) contributes to the decreasing trend of DAOD. As shown in Fig. 16, among the six PSAs, the satellite data show a consistent interannual declining trend of DAOD in EAS-5 (southern Gobi Desert) at a rate of $-4.8 \% \mathrm{yr}^{-1}$ and $-2.8 \% \mathrm{yr}^{-1}$ for MODIS and CALIOP, respectively. In spring, DAOD in EAS-5 shows a significantly declining trend at a rate of $-5.6 \% \mathrm{yr}^{-1}$ and $-3.3 \% \mathrm{yr}^{-1}$ for MODIS and CALIOP (Fig. S9). Figure 17 assesses the correlation between DAOD in EAS-5 and DAOD in NWP based on MODIS and CALIOP, respectively. For annual mean DAOD from 2007 to 2019, both sensors show a good correlation between EAS-5 and NWP with $R \approx 0.6(p=0.02)$. In spring, the correlation of DAOD from two regions is good based on CALIOP $(R=0.6, p=0.03)$, while a weaker correlation $(R=0.53, p=0.07)$ was found based on MODIS. We further examine potential factors contribute to the declining trend of DAOD in ESA-5 (Qian et al., 2002; Kurosaki and Mikami 2003; Lee and Sohn, 2011). The first row in Fig. 18 shows the springtime trend of MODIS Enhanced Vegetation Index (EVI), MERRA-2 near-surface (at $10 \mathrm{~m}$ ) wind speed (Carvalho, 2019), and precipitation (Reichle et al., 2017) in the EAS-5 region. EVI and precipitation show a statistically 


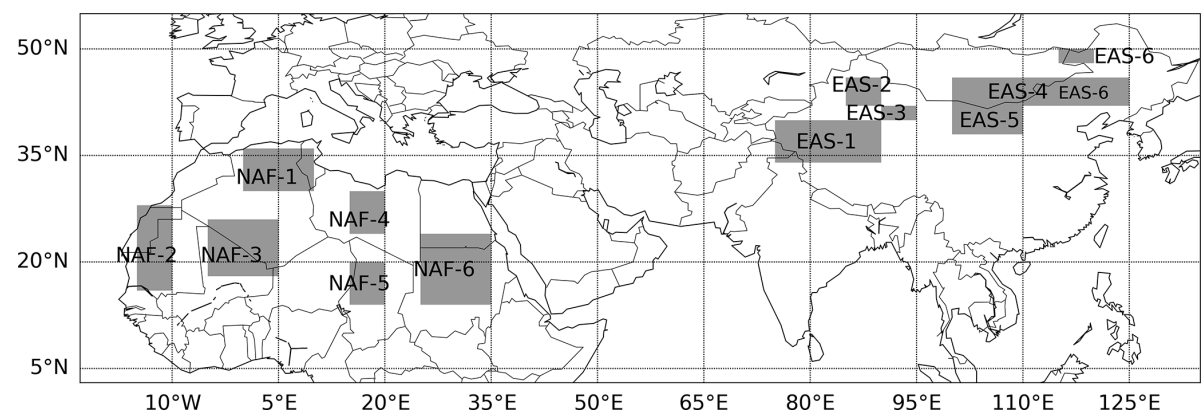

Figure 12. Six dust potential source subregions in Northern Africa (NAF) and Eastern Asia (EAS) based on Figs. 1 and 2 in Formenti et al. (2011). PSA NAF-1 $\left(30-36^{\circ} \mathrm{N}, 0-9^{\circ} \mathrm{E}\right)$, PSA NAF-2 $\left(16-28^{\circ} \mathrm{N}, 10-15^{\circ} \mathrm{W}\right)$, PSA NAF-3 $\left(18-26^{\circ} \mathrm{N}, 5^{\circ} \mathrm{W}-5^{\circ} \mathrm{E}\right)$, PSA NAF-4 $(24-$ $\left.30^{\circ} \mathrm{N}, 15-20^{\circ} \mathrm{E}\right)$, PSA NAF-5 $\left(14-20^{\circ} \mathrm{N}, 15-20^{\circ} \mathrm{E}\right)$, PSA NAF-6 $\left(14-24^{\circ} \mathrm{N}, 25-35^{\circ} \mathrm{E}\right)$; EAS-1 $\left(34-40^{\circ} \mathrm{N}, 75-90^{\circ} \mathrm{E}\right)$; EAS-2 $\left(44-46^{\circ} \mathrm{N}\right.$,

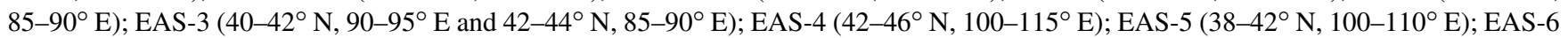
$\left(42-46^{\circ} \mathrm{N}, 115-125^{\circ} \mathrm{E}\right.$ and $\left.48-50^{\circ} \mathrm{N}, 115-120^{\circ} \mathrm{E}\right)$.
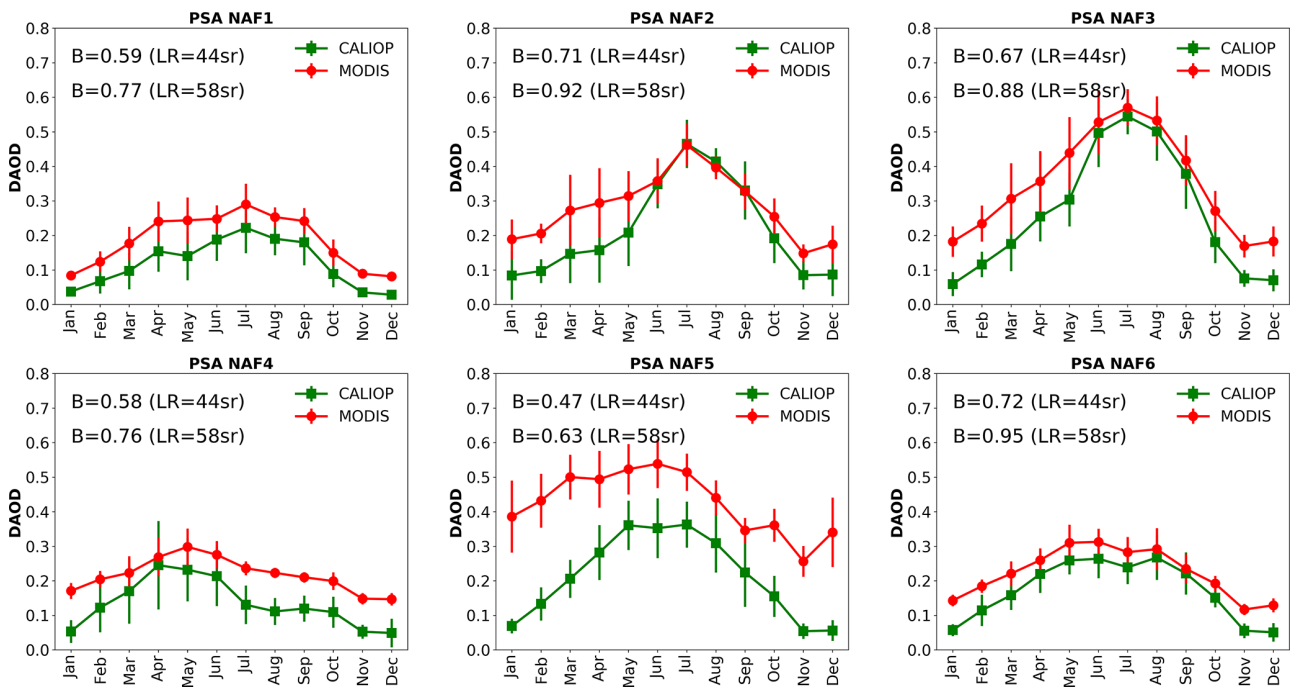

Figure 13. Annual cycle of 13-year (2007-2019) monthly mean DAOD over the six PSAs of north African dust. The CALIOP DAOD annual cycle shown in the figure is derived from backscatter coefficients using LR of 44 sr. The mean bias $(B)$ is computed as the average of CALIOP DAOD/MODIS DAOD ratios of all data pairs. $B=1,>1$, and $<1$ indicate no bias, high bias, and low bias. The mean bias $(B)$ associated with CALIOP DAOD based on $\mathrm{LR}=44$ and $58 \mathrm{sr}$ is shown in the upper left of each panel.

significant $(p<0.05)$ increasing trend with $R=0.82$ and $R=0.58$, respectively. Surface wind speed shows a statistically significant $(p<0.05)$ decreasing trend with $R=0.66$. The second row in Fig. 18 shows the correlations of the three factors with MODIS DAOD and CALIOP DAOD, respectively. Clearly, EVI is anti-correlated with both MODIS and CALIOP DAOD with $|R|>0.7$ and $p<0.05$. Surface wind speed is correlated with MODIS DAOD and CALIOP DAOD with $|R|>0.6$ and $p<0.05$, while the correlation with precipitation is not statistically significant $(p>0.05)$. Note that EVI and surface wind speed are not independent variables that affect dust emissions. An increase of EVI or vegetation cover could reduce the surface wind speed. However, given the relatively coarse resolution of MERRA-2, the surface wind speed trend may largely reflect the change in atmo- spheric circulations other than a local wind decrease induced by more vegetation. The precipitation shows no statistically significant correlation with MODIS and CALIOP DAOD.

As discussed earlier, our results suggest that the decrease of NWP DAOD is likely a result of the decreasing dust events in Asian deserts (i.e., EAS-5 Gobi) in turn likely due to change of vegetation. This is also reported in several recent studies. Sternberg et al. (2015) found that Gobi Desert contracted from 2000 to 2012 due to increased moisture availability. Song et al. (2016) used an integrated wind erosion modeling system to simulate the spring dust emissions in northern China over the period of 1982 to 2011. They found a significant decrease of the magnitude of spring dust event in China which is attributed to both climate change and local mitigation strategies. Similarly, An et al. (2018) also noted 

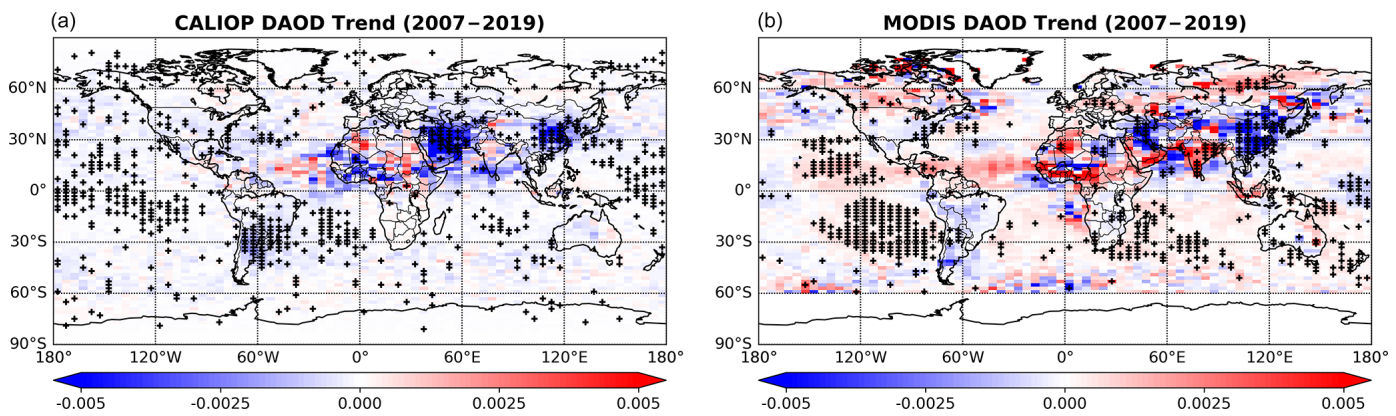

Figure 14. Global map of DAOD trend based on CALIOP (a) and MODIS (b) dust climatology data over 2007-2019 period. Red and blue represents increasing and decreasing trend, respectively. The " + " symbol denotes trends with $p$ value $<0.05$, which are considered as statistically meaningful trends.
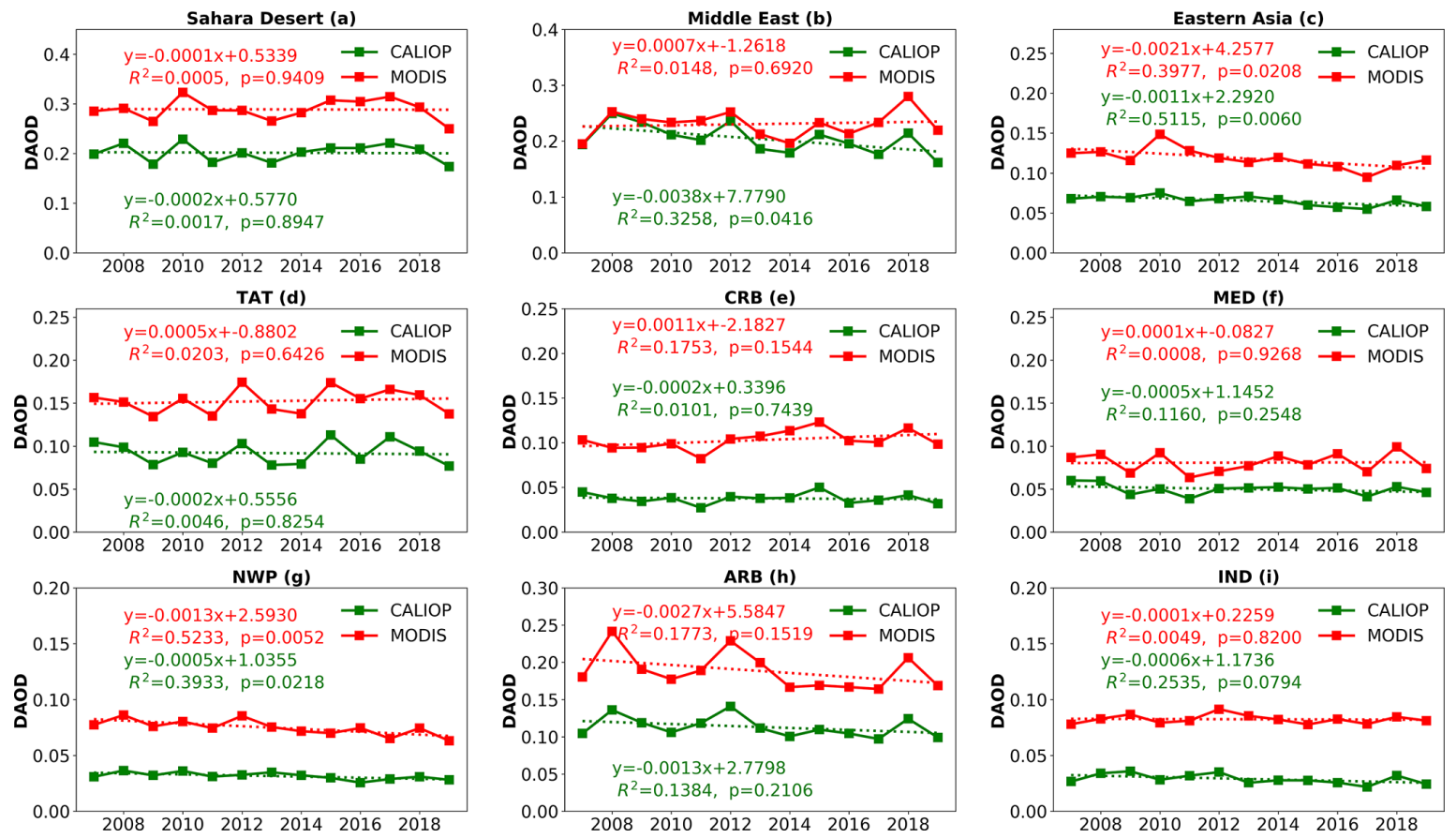

Figure 15. DAOD interannual variability over main dust source regions (a-c) and dust outflow regions (d-i) revealed by CALIOP (green curve) and MODIS (red curve) observations.

a significant decrease of dust storm event in East Asia after analyzing observational data from ground stations, numerical modeling, and vegetation indices obtained from both satellite and reanalysis data. Over the last few decades, the Chinese government has been taking actions to restore overgrazed land in Inner Mongolia; the enlarged vegetation coverage and the expected earlier vegetation green-up due to global warming could have mitigated dust activity in this region (Fan et al., 2014). Together with the results from our analysis, along with the aforementioned recent studies, suggest that the decreasing springtime DAOD trend in the NWP region is a result of the decline of dust activities in Inner Mongolia (i.e., EAS-5), which is likely linked to vegetation coverage changes in recent years as a result of China's mitigation projects to hold back desertification.

Some caveats must be mentioned, however, when interpreting the trend analysis here. First of all, due to the limitations of the satellite data record, we have only 13 years worth of CALIOP data and 17 years worth of MODIS data available. Other climate variabilities, such as the El NiñoSouthern Oscillation (ENSO), could confound the trend analysis. For example, Abish and Mohanakumar (2013) shows that La Niña (El Niño) weakens (strengthens) the zonal circulation over the Indian subcontinent, which results in low (high) aerosol concentration over the Indian subcontinent transported from the Arabian Desert over the period. Gong et al. (2005) also show the impact of ENSO on the inter- 
Table 5. DAOD trend over major dust-laden regions based on MODIS and CALIOP observations. The changing rate of DAOD trend is shown in a sequence of annual/spring/summer/fall/winter in each cell of the table. Those statistically meaningful trends with $p<0.05$ are shown in bold.

\begin{tabular}{lrrrrr|rrrrr}
\hline & \multicolumn{4}{c}{ MODIS [\% $\mathrm{yr}^{-1}$ ] } & \multicolumn{4}{c}{ CALIOP [\% $\mathrm{yr}^{-1}$ ] } \\
\cline { 2 - 11 } & Annual & MAM & JJA & SON & DJF & Annual & MAM & JJA & SON & DJF \\
\hline Sahara (a) & -0.04 & -0.84 & 0.21 & 0.29 & 0.51 & -0.09 & -0.93 & 0.34 & -0.52 & 0.55 \\
Middle East (b) & 0.32 & -0.61 & -0.02 & $\mathbf{1 . 8 0}$ & 1.37 & $\mathbf{- 1 . 8 4}$ & -2.36 & -1.86 & $\mathbf{- 2 . 4 6}$ & -0.09 \\
Eastern Asia (c) & $\mathbf{- 1 . 7 4}$ & $\mathbf{- 3 . 4 8}$ & -0.28 & -0.33 & -0.56 & $\mathbf{- 1 . 7 0}$ & $\mathbf{- 2 . 4 6}$ & $\mathbf{- 1 . 9 9}$ & -0.45 & -1.42 \\
TAT (d) & 0.34 & -0.68 & -0.03 & 1.68 & 1.32 & -0.25 & -1.41 & -0.07 & 0.91 & -0.09 \\
CRB (e) & 1.10 & 0.78 & 0.94 & $\mathbf{1 . 5 9}$ & $\mathbf{1 . 9 7}$ & -0.40 & -1.39 & -0.34 & 0.79 & -1.09 \\
MED (f) & 0.10 & 0.32 & 0.49 & -0.71 & 0.03 & -1.09 & -1.07 & -1.63 & -1.20 & -0.52 \\
NWP (g) & $\mathbf{- 1 . 6 7}$ & $\mathbf{- 2 . 3 3}$ & $\mathbf{- 1 . 9 3}$ & 0.63 & -1.35 & $\mathbf{- 1 . 5 8}$ & $\mathbf{- 3 . 0 1}$ & $\mathbf{- 2 . 8 9}$ & -0.40 & -0.19 \\
ARB (h) & -1.42 & -0.72 & -1.81 & $\mathbf{- 1 . 8 5}$ & -0.31 & -1.17 & -1.70 & -0.46 & $\mathbf{- 3 . 6 0}$ & -0.06 \\
IND (i) & -0.09 & -0.51 & 0.40 & 0.38 & -0.89 & -1.96 & -2.92 & -2.43 & -0.21 & -0.54 \\
\hline
\end{tabular}
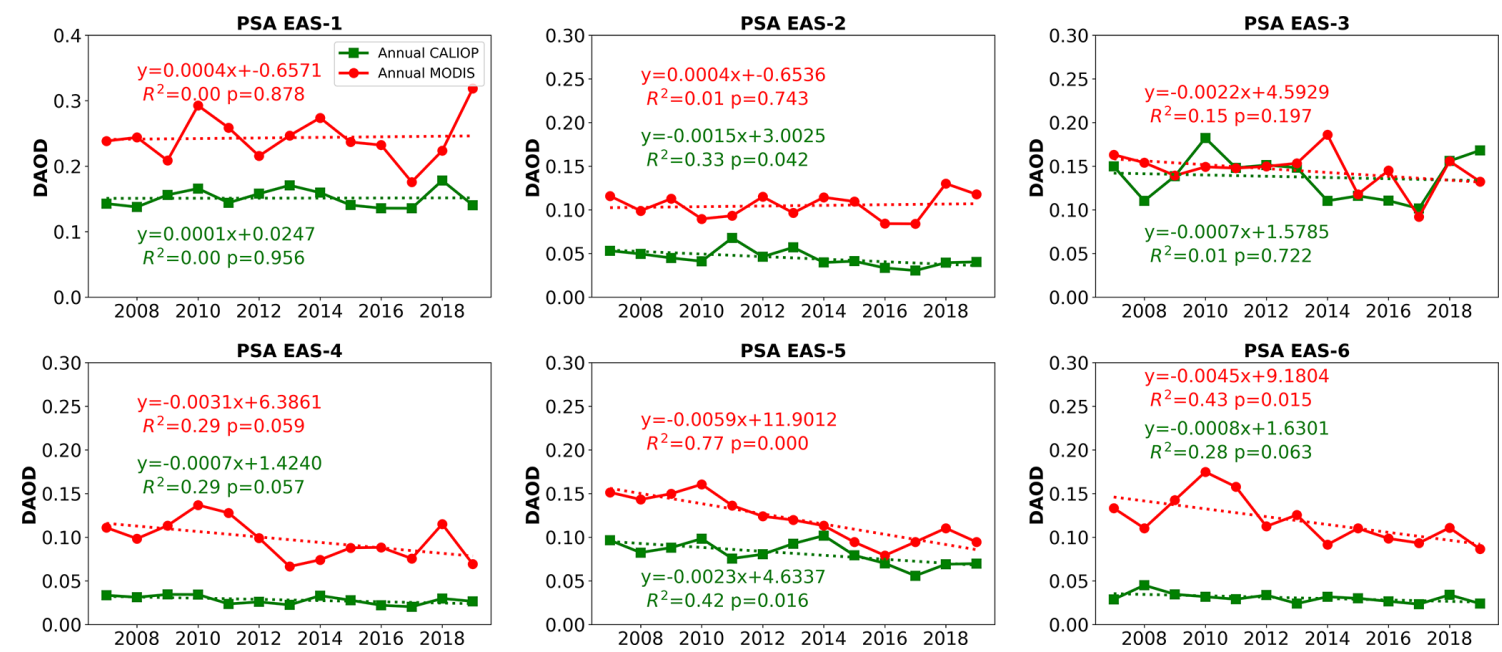

Figure 16. Interannual variability of CALIOP (green) and MODIS (red) DAOD in the six potential dust source areas in eastern Asia (refer to Fig. 8).
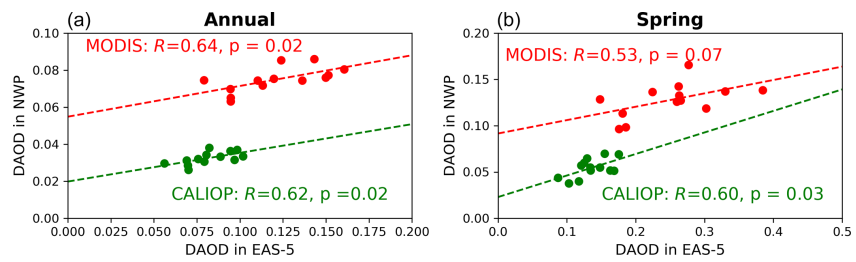

Figure 17. Correlation between DAOD in EAS-5 (southern Gobi Desert) and DAOD in NWP for annual mean (a) and springtime average (b).

annual variability of Asian dust loading and deposition. According to the NOAA Oceanic Niño Index (ONI), the climate switched from a strong La Niña phase in 2010-2011 to a strong El Niño phase in 2015-2016. However, the potential impact of ENSO on the dust interannual variability is beyond the scope of this study and will be left for the future research.

\section{Summary and conclusion}

We derive two observation-based global monthly mean dust aerosol optical depth (DAOD) climatological datasets from 2007 to 2019 with a $2^{\circ}$ (latitude) $\times 5^{\circ}$ (longitude) spatial resolution, one based on CALIOP and the other on MODIS observations. Our product captures very well as much hotspots along the "dust belt" region well, as weaker signals in other dust-active regions such as the southwestern United States, Patagonian Desert in South America, central Australia, and South Africa (Fig. 5). Since DAOD climatology product contains and mixes the information of the intensity and frequency of dust activities, we introduce the conditional DAOD product, which diminishes impacts from dust frequency by excluding dust-free cases in the average. The comparison between DAOD climatology data and conditional DAOD data suggests that dust activities in those regions are highly episodic. The two data records compare rea- 

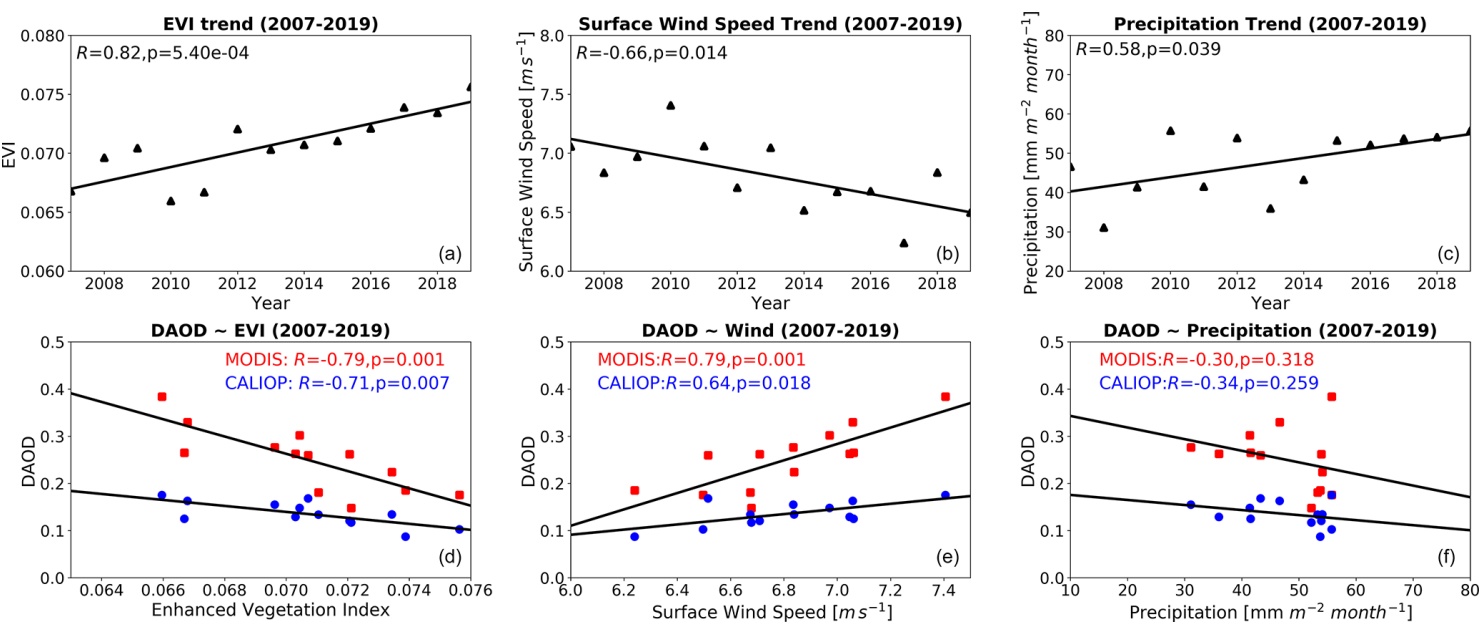

Figure 18. The trend of Enhanced Vegetation Index (EVI), surface wind speed, and precipitation and their correlation with DAOD in spring in the EAS-5 region. Panels (a)-(c) show the trend of EVI, surface wind speed, and precipitation. Panels (d)-(f) show the correlation of EVI, surface wind speed, and precipitation with MODIS-based DAOD and CALIOP-based DAOD, respectively. In addition, the time series of EVI versus DAOD, wind speed versus DAOD, and precipitation versus DAOD is shown in Fig. S10.

sonably well with the results reported in previous studies and the collocated AERONET coarse-mode AOD. The comparison of our MODIS-based and CALIOP-based DAOD with AERONET COD indicates that MODIS overestimates DAOD, while CALIOP underestimates DAOD. It is highly probable that the true DAODs fall between MODIS and CALIOP DAOD.

CALIOP distinguishes dust aerosols based on its nonspherical shape, whereas MODIS separates dust aerosols from others based on its large size characteristics. The discrepancy in dust retrieval based on two instruments are expected due to the uncertainty associated with their TAOD retrieval and the uncertainty associated with their different mechanism in dust detection and separation. The comparison between CALIOP dust retrieval and MODIS dust retrieval facilitate a better understanding of advantages and limitations of each dust product and also provide some insights on dust morphology and dust size. Through the comparison, we found generally CALIOP-based DAOD correlates well with MODIS-based DAOD over dust-laden regions such as Sahara $(R=0.78)$, TAT $(R=0.84)$, CRB $(R=0.75)$, and ARB $(R=0.85)$, but with CALIOP-based DAOD $18 \%$, $34 \%, 54 \%$, and $31 \%$ lower than MODIS-based DAOD over those regions, respectively. This result is consistent with the different treatment of the dust-pollution mixtures in the dust separation approaches of two instruments. Applying LR of $58 \mathrm{sr}$ to Saharan dust reduce the difference from $18 \%$ to $8 \%$ over the Sahara and from $34 \%$ to $12 \%$ over TAT. Over the Sahara, the good agreement in DAOD between the two sensors (bias of $8 \%$ and $R=0.78$ ) suggests that dust aerosols are irregular non-spherical and at the same time large in size in this region. In some regions such as NWP, the DAOD correlation between two sensors is quite low. There could be many reasons for this; for example, the total TAOD retrievals from MODIS have larger uncertainty due to cloud contamination, or the DAOD retrieval from CALIOP may miss coarse spherical dust-pollution mixtures.

The interannual variability of DAOD over dust-laden regions shows a clear trend in eastern Asia at a rate of $-1.7 \% \mathrm{yr}^{-1}$ based on two sensors. Over the outflow region of eastern Asia, DAOD in the NWP region shows a clear trend at a rate of $-1.6 \% \mathrm{yr}^{-1}$ and $-1.7 \% \mathrm{yr}^{-1}$ based on CALIOP and MODIS respectively, this trend is mainly attributed to the decreasing trend in spring with a rate of $-3.0 \% \mathrm{yr}^{-1}$ based on CALIOP and $-2.3 \% \mathrm{yr}^{-1}$ based on MODIS. Further investigation of DAOD trend in six dust source areas in eastern Asia, where NWP dust aerosols come from, shows that there is an obvious decreasing trend in DAOD during 2007-2019 over the southern Gobi Desert based on both CALIOP and MODIS dust retrievals. The decreasing trend of DAOD is correlated significantly with the vegetation index and surface wind speed in the area, whereas there is almost no correlation with the precipitation.

The two observation-based DAOD climatological datasets derived in this study can be highly valuable for many dustrelated studies. For example, they can be used to assess dust direct radiative effects (e.g., Kok et al., 2017), study aerosolcloud interactions (e.g., Choi et al., 2010; Tan et al., 2014), and identify global and regional dust trends and variabilities. They may also be used to evaluate the dust simulations in global climate models (e.g., Wu et al., 2020a, b). On the other hand, the current study faces several important limitations. For example, as explained in Sect. 4, the current MODISbased DAOD climatology suffers from the land-to-ocean discontinuity problem due to the use of two AOD products and potential cloud contaminations. The small horizontal sam- 
pling rate of CALIOP is also an important limitation. These problems are beyond the scope of this study and will be left for future research.

Data availability. The global DAOD and dust vertical extinction coefficient climatology data derived from CALIOP in this study and the MODIS DAOD retrieval data over land and ocean are available at https://drive.google.com/drive/folders/ 1aQVupe7govPwR6qmsqUbR4fJQsp1DBCX?usp=sharing (Song et al., 2021).

The MODIS EVI data can be downloaded from https:// lpdaac.usgs.gov/products/myd13c2v006/\#tools (Didan, 2015). The MERRA-2 surface wind speed and precipitation data are available at https://disc.sci.gsfc.nasa.gov/datasets/M2T1NXFLX_5.12. 4/summary?keywords=\%22MERRA-2\%22 (Global Modeling and Assimilation Office, 2015).

Supplement. The supplement related to this article is available online at: https://doi.org/10.5194/acp-21-13369-2021-supplement.

Author contributions. ZZ and HY conceived the scientific ideas, and QS did the analysis and completed the initial draft of the manuscript. HY provided MODIS over-ocean dust retrievals; PG provided MODIS overland dust retrievals. JC contributed in analysing the interannual variability of DAOD in the Gobi Desert when he was an intern at NASA Goddard Space Flight center in 2020. HY and PG gave many suggestions for the study and contributed significantly to the revision of the manuscript.

Competing interests. The authors declare that they have no conflict of interest.

Disclaimer. Publisher's note: Copernicus Publications remains neutral with regard to jurisdictional claims in published maps and institutional affiliations.

Acknowledgements. Qianqian Song and Zhibo Zhang cordially acknowledge the funding support from the Future Investigators in NASA Earth and Space Science and Technology (FINESST). Zhibo Zhang's research is supported by a NASA grant (no. 80NSSC20K0130) from the CALIPSO and CloudSat program managed by David Considine. Hongbin Yu was supported by NASA's the Science of Terra, Aqua, and Suomi-NPP and the CALIPSO/CloudSat Science Team programs administered by Hal Maring and David Considine, respectively. The computations in this study were performed at the UMBC High Performance Computing Facility (HPCF). The facility is supported by the US National Science Foundation through the MRI program (grant nos. CNS0821258 and CNS-1228778) and the SCREMS program (grant no. DMS-0821311), with substantial support from UMBC. The MODIS aerosol data were obtained from the NASA Level-1 and Atmosphere Archive and Distribution System (LAADS) web page (https://ladsweb.nascom.nasa.gov/, last access: 9 February 2021). The CALIOP aerosol products were obtained from NASA Langley Research Center Atmospheric Science Data Center (https: //eosweb.larc.nasa.gov/, last access: 9 February 2019).

Financial support. This research has been supported by the National Aeronautics and Space Administration (grant nos. 80NSSC20K0130, 80NSSC19K1345, CNS-0821258, CNS1228778, and DMS-0821311).

Review statement. This paper was edited by Xiaohong Liu and reviewed by three anonymous referees.

\section{References}

Abish, B. and Mohanakumar, K.: Absorbing aerosol variability over the Indian subcontinent and its increasing dependence on ENSO, Global Planet. Change, 106, 13-19, https://doi.org/10.1016/j.gloplacha.2013.02.007, 2013.

Albrecht, B. A.: Aerosols, Cloud Microphysics, and Fractional Cloudiness, Science, 245, 1227-1230, https://doi.org/10.1126/science.245.4923.1227, 1989.

Amiridis, V., Wandinger, U., Marinou, E., Giannakaki, E., Tsekeri, A., Basart, S., Kazadzis, S., Gkikas, A., Taylor, M., Baldasano, J., and Ansmann, A.: Optimizing CALIPSO Saharan dust retrievals, Atmos. Chem. Phys., 13, 12089-12106, https://doi.org/10.5194/acp-13-12089-2013, 2013.

An, L., Che, H., Xue, M., Zhang, T., Wang, H., Wang, Y., Zhou, C., Zhao, H., Gui, K., and Zheng, Y.: Temporal and spatial variations in sand and dust storm events in East Asia from 2007 to 2016: Relationships with surface conditions and climate change, Sci. Total Environ., 633, 452-462, 2018.

Anderson, T. L., Wu, Y., Chu, D. A., Schmid, B., Redemann, J., and Dubovik, O.: Testing the MODIS satellite retrieval of aerosol fine-mode fraction, J. Geophys. Res.-Atmos., 110, 1-16, https://doi.org/10.1029/2005JD005978, 2005.

Ansmann, A., Tesche, M., Seifert, P., Groß, S., Freudenthaler, V., Apituley, A., Wilson, K. M., Serikov, I., Linné, H., Heinold, B., Hiebsch, A., Schnell, F., Schmidt, J., Mattis, I., Wandinger, U., and Wiegner, M.: Ash and fine-mode particle mass profiles from EARLINET-AERONET observations over central Europe after the eruptions of the Eyjafjallajökull volcano in 2010, J. Geophys. Res.-Atmos., 116, D00U02, https://doi.org/10.1029/2010JD015567, 2011.

Ansmann, A., Seifert, P., Tesche, M., and Wandinger, U.: Profiling of fine and coarse particle mass: case studies of Saharan dust and Eyjafjallajökull/Grimsvötn volcanic plumes, Atmos. Chem. Phys., 12, 9399-9415, https://doi.org/10.5194/acp12-9399-2012, 2012.

Baars, H., Kanitz, T., Engelmann, R., Althausen, D., Heese, B., Komppula, M., Preißler, J., Tesche, M., Ansmann, A., Wandinger, U., Lim, J.-H., Ahn, J. Y., Stachlewska, I. S., Amiridis, V., Marinou, E., Seifert, P., Hofer, J., Skupin, A., Schneider, F., Bohlmann, S., Foth, A., Bley, S., Pfüller, A., Giannakaki, E., Lihavainen, H., Viisanen, Y., Hooda, R. K., Pereira, S. N., Bortoli, D., Wagner, F., Mattis, I., Janicka, L., Markowicz, 
K. M., Achtert, P., Artaxo, P., Pauliquevis, T., Souza, R. A. F., Sharma, V. P., van Zyl, P. G., Beukes, J. P., Sun, J., Rohwer, E. G., Deng, R., Mamouri, R.-E., and Zamorano, F.: An overview of the first decade of PollyNET: an emerging network of automated Raman-polarization lidars for continuous aerosol profiling, Atmos. Chem. Phys., 16, 5111-5137, https://doi.org/10.5194/acp16-5111-2016, 2016.

Burton, S. P., Ferrare, R. A., Hostetler, C. A., Hair, J. W., Rogers, R. R., Obland, M. D., Butler, C. F., Cook, A. L., Harper, D. B., and Froyd, K. D.: Aerosol classification using airborne High Spectral Resolution Lidar measurements - methodology and examples, Atmos. Meas. Tech., 5, 73-98, https://doi.org/10.5194/amt-5-732012, 2012.

Carvalho, D.: An Assessment of NASA's GMAO MERRA2 Reanalysis Surface Winds, J. Climate, 32, 8261-8281, https://doi.org/10.1175/JCLI-D-19-0199.1, 2019.

Chen, C., Dubovik, O., Henze, D. K., Lapyonak, T., Chin, M., Ducos, F., Litvinov, P., Huang, X., and Li, L.: Retrieval of desert dust and carbonaceous aerosol emissions over Africa from POLDER/PARASOL products generated by the GRASP algorithm, Atmos. Chem. Phys., 18, 12551-12580, https://doi.org/10.5194/acp-18-12551-2018, 2018.

Chimot, J., Veefkind, J. P., Vlemmix, T., de Haan, J. F., Amiridis, V., Proestakis, E., Marinou, E., and Levelt, P. F.: An exploratory study on the aerosol height retrieval from OMI measurements of the $477 \mathrm{~nm} \mathrm{O}-\mathrm{O}_{2}$ spectral band using a neural network approach, Atmos. Meas. Tech., 10, 783-809, https://doi.org/10.5194/amt-10-783-2017, 2017.

Choi, Y.-S., Lindzen, R. S., Ho, C.-H., and Kim, J.: Space observations of cold-cloud phase change, P. Natl. Acad. Sci. USA, 107, 11211, https://doi.org/10.1073/pnas.1006241107, 2010.

Clarisse, L., Clerbaux, C., Franco, B., Hadji-Lazaro, J., Whitburn, S., Kopp, A. K., Hurtmans, D., and Coheur, P.: A decadal data set of global atmospheric dust retrieved from IASI satellite measurements, J. Geophys. Res.-Atmos., 124, 1618-1647, 2019.

Di Biagio, C., Balkanski, Y., Albani, S., Boucher, O., and Formenti, P.: Direct Radiative Effect by Mineral Dust Aerosols Constrained by New Microphysical and Spectral Optical Data, Geophys. Res. Lett., 47, e2019GL086186, https://doi.org/10.1029/2019GL086186, 2020.

Didan, K.: MYD13C2 MODIS/Aqua Vegetation Indices Monthly L3 Global 0.05Deg CMG V006, NASA EOSDIS Land Processes DAAC [data set], https://doi.org/10.5067/MODIS/MYD13C2.006 (last access: 3 September 2021), 2015.

Dubovik, O., Sinyuk, A., Lapyonok, T., Holben, B. N., Mishchenko, M., Yang, P., Eck, T. F., Volten, H., Munoz, O., Veihelmann, B., van der Zande, W. J., Leon, J. F., Sorokin, M., and Slutsker, I.: Application of spheroid models to account for aerosol particle nonsphericity in remote sensing of desert dust, J. Geophys. Res., 111, D11208, https://doi.org/10.1029/2005jd006619, 2006.

Eck, T. F., Holben, B. N., Reid, J. S., Dubovik, O., Smirnov, A., O’Neill, N. T., Slutsker, I., and Kinne, S.: Wavelength dependence of the optical depth of biomass burning, urban, and desert dust aerosols, J. Geophys. Res.-Atmos., 104, 31333 31349, https://doi.org/10.1029/1999JD900923, 1999.

Esselborn, M., Wirth, M., Fix, A., Weinzierl, B., Rasp, K., Tesche, M., and Petzold, A.: Spatial distribution and optical properties of
Saharan dust observed by airborne high spectral resolution lidar during SAMUM 2006, Tellus B, 61, 131-143, 2009.

Evan, A. T., Dunion, J., Foley, J. A., Heidinger, A. K., and Velden, C. S.: New evidence for a relationship between Atlantic tropical cyclone activity and African dust outbreaks, Geophys. Res. Lett., 33, L19813, https://doi.org/10.1029/2006g1026408, 2006.

Fan, B., Guo, L., Li, N., Chen, J., Lin, H., Zhang, X., Shen, M., Rao, Y., Wang, C., and Ma, L.: Earlier vegetation greenup has reduced spring dust storms, Sci. Rep.-UK, 4, 1-6, https://doi.org/10.1038/srep06749, 2014.

Fiebig, M., Petzold, A., Wandinger, U., Wendisch, M., Kiemle, C., Stifter, A., Ebert, M., Rother, T., and Leiterer, U.: Optical closure for an aerosol column: Method, accuracy, and inferable properties applied to a biomass-burning aerosol and its radiative forcing, J. Geophys. Res., 107, 8130, https://doi.org/10.1029/2000JD000192, 2002.

Formenti, P., Schütz, L., Balkanski, Y., Desboeufs, K., Ebert, M., Kandler, K., Petzold, A., Scheuvens, D., Weinbruch, S., and Zhang, D.: Recent progress in understanding physical and chemical properties of African and Asian mineral dust, Atmos. Chem. Phys., 11, 8231-8256, https://doi.org/10.5194/acp11-8231-2011, 2011.

Gasteiger, J., Wiegner, M., Groß, S., Freudenthaler, V., Toledano, C., Tesche, M., and Kandler, K.: Modelling lidar-relevant optical properties of complex mineral dust aerosols, Tellus B, 63, 725741, https://doi.org/10.1111/j.1600-0889.2011.00559.x, 2011.

Ge, J. M., Huang, J. P., Xu, C. P., Qi, Y. L., and Liu, H. Y.: Characteristics of Taklimakan dust emission and distribution: A satellite and reanalysis field perspective, J. Geophys. Res.-Atmos., 119, 11772-11783, https://doi.org/10.1002/2014JD022280, 2014.

Gelaro, R., McCarty, W., Suárez, M. J., Todling, R., Molod, A., Takacs, L., Randles, C. A., Darmenov, A., Bosilovich, M. G., Reichle, R., Wargan, K., Coy, L., Cullather, R., Draper, C., Akella, S., Buchard, V., Conaty, A., da Silva, A. M., Gu, W., Kim, G. K., Koster, R., Lucchesi, R., Merkova, D., Nielsen, J. E., Partyka, G., Pawson, S., Putman, W., Rienecker, M., Schubert, S. D., Sienkiewicz, M., and Zhao, B.: The modern-era retrospective analysis for research and applications, version 2 (MERRA-2), J. Climate, 30, 5419-5454, https://doi.org/10.1175/JCLI-D-160758.1, 2017.

Getzewich, B. J., Vaughan, M. A., Hunt, W. H., Avery, M. A., Powell, K. A., Tackett, J. L., Winker, D. M., Kar, J., Lee, K.P., and Toth, T. D.: CALIPSO lidar calibration at $532 \mathrm{~nm}$ : version 4 daytime algorithm, Atmos. Meas. Tech., 11, 6309-6326, https://doi.org/10.5194/amt-11-6309-2018, 2018.

Ginoux, P., Garbuzov, D., and Hsu, N. C.: Identification of anthropogenic and natural dust sources using moderate resolution imaging spectroradiometer (MODIS) deep blue level 2 data, J. Geophys. Res.-Atmos., 115, 1-10, https://doi.org/10.1029/2009JD012398, 2010.

Ginoux, P., Prospero, J. M., Gill, T. E., Hsu, N. C., and Zhao, M.: Global-scale attribution of anthropogenic and natural dust sources and their emission rates based on MODIS Deep Blue aerosol products, Rev. Geophys., 50, RG3005, https://doi.org/10.1029/2012RG000388, 2012.

Gkikas, A., Proestakis, E., Amiridis, V., Kazadzis, S., Di Tomaso, E., Tsekeri, A., Marinou, E., Hatzianastassiou, N., and Pérez García-Pando, C.: ModIs Dust AeroSol (MIDAS): a global fine- 
resolution dust optical depth data set, Atmos. Meas. Tech., 14, 309-334, https://doi.org/10.5194/amt-14-309-2021, 2021.

Global Modeling and Assimilation Office (GMAO): MERRA-2 tavg1_2d_flx_Nx: 2d,1-Hourly, Time-Averaged, SingleLevel, Assimilation, Surface Flux Diagnostics V5.12.4, Greenbelt, MD, USA, Goddard Earth Sciences Data and Information Services Center (GES DISC) [data set], https://doi.org/10.5067/7MCPBJ41Y0K6 (last access: 9 February 2021), 2015.

Gong, S. L., Zhang, X. Y., Zhao, T. L., Zhang, \# X B, Barrie, L. A., Mckendry, I. G., and Zhao, C. S.: A simulated Climatology of Asian Dust Aerosol and Its Trans-Pacific Transport. Part II: Interannual Variability and Climate Connections, Atmospheric Research and Environment Program, World Meteorological Organization, 2005.

Griffin, D. W.: Atmospheric Movement of Microorganisms in Clouds of Desert Dust and Implications for Human Health, Clin. Microbiol. Rev., 20, 459-477, https://doi.org/10.1128/CMR.00039-06, 2007.

Grousset, F., Ginoux, P., Bory, A., and Biscaye, P.: Case study of a Chinese dust plume reaching the French Alps, Geophys. Res. Lett., 30, 1277, https://doi.org/10.1029/2002GL016833, 2003.

Hansen, J., Sato, M., and Ruedy, R.: Radiative forcing and climate response, J. Geophys. Res., 102, 6831-6864, https://doi.org/10.1029/96jd03436, 1997.

Hayasaka, T., Satake, S., Shimizu, A., Sugimoto, N., Matsui, I., Aoki, K., and Muraji, Y.: Vertical distribution and optical properties of aerosols observed over Japan during the Atmospheric Brown Clouds-East Asia Regional Experiment 2005, J. Geophys. Res.-Atmos., 112, D22S35, https://doi.org/10.1029/2006JD008086, 2007.

Hsu, N. C., Tsay, S. C., King, M. D., and Herman, J. R.: Aerosol properties over bright-reflecting source regions, IEEE T. Geosci. Remote Sens., 42, 557-569, https://doi.org/10.1109/TGRS.2004.824067, 2004.

Hsu, N. C., Jeong, M.-J., Bettenhausen, C., Sayer, A. M., Hansell, R., Seftor, C. S., Huang, J., and Tsay, S.-C.: Enhanced Deep Blue aerosol retrieval algorithm: The second generation, J. Geophys. Res.-Atmos., 118, 9296-9315, https://doi.org/10.1002/jgrd.50712, 2013.

Huang, J., Minnis, P., Yi, Y., Tang, Q., Wang, X., Hu, Y., Liu, Z., Ayers, K., Trepte, C., and Winker, D.: Summer dust aerosols detected from CALIPSO over the Tibetan Plateau, Geophys. Res. Lett., 34, L18805, https://doi.org/10.1029/2007GL029938, 2007.

Huang, J., Minnis, P., Chen, B., Huang, Z., Liu, Z., Zhao, Q., Yi, Y., and Ayers, J. K.: Long-range transport and vertical structure of Asian dust from CALIPSO and surface measurements during PACDEX, J. Geophys. Res.-Atmos., 113, https://doi.org/10.1029/2008JD010620, 2008.

Huang, Y., Kok, J. F., Kandler, K., Lindqvist, H., Nousiainen, T., Sakai, T., Adebiyi, A., and Jokinen, O.: Climate Models and Remote Sensing Retrievals Neglect Substantial Desert Dust Asphericity, Geophys. Res. Lett., 47, e2019GL086592, https://doi.org/10.1029/2019GL086592, 2020.

Järvinen, E., Kemppinen, O., Nousiainen, T., Kociok, T., Möhler, O., Leisner, T., and Schnaiter, M.: Laboratory investigations of mineral dust near-backscattering depolarization ratios, J. Quant. Spectrosc. Ra., 178, 192-208, https://doi.org/10.1016/j.jqsrt.2016.02.003, 2016.
Jickells, T. D., An, Z. S., Andersen, K. K., Baker, A. R., Bergametti, G., Brooks, N., Cao, J. J., Boyd, P. W., Duce, R. A., Hunter, K. A., Kawahata, H., Kubilay, N., Laroche, J., Liss, P. S., Mahowald, N., Prospero, J. M., Ridgwell, A. J., Tegen, I., and Torres, R.: Global Iron Connections Between Desert Dust, Ocean Biogeochemistry, and Climate, Science, 308, 67-71, 2005.

Kalashnikova, O. V, Kahn, R., Sokolik, I. N., and Li, W.: Ability of multiangle remote sensing observations to identify and distinguish mineral dust types: Optical models and retrievals of optically thick plumes, J. Geophys. Res.-Atmos., 110, D18S14, https://doi.org/10.1029/2004JD004550, 2005.

Kar, J., Vaughan, M. A., Lee, K.-P., Tackett, J. L., Avery, M. A., Garnier, A., Getzewich, B. J., Hunt, W. H., Josset, D., Liu, Z., Lucker, P. L., Magill, B., Omar, A. H., Pelon, J., Rogers, R. R., Toth, T. D., Trepte, C. R., Vernier, J.-P., Winker, D. M., and Young, S. A.: CALIPSO lidar calibration at $532 \mathrm{~nm}$ : version 4 nighttime algorithm, Atmos. Meas. Tech., 11, 1459-1479, https://doi.org/10.5194/amt-11-1459-2018, 2018.

Kaufman, Y. J., Koren, I., Remer, L. A., Tanré, D., Ginoux, P., and Fan, S.: Dust transport and deposition observed from the Terra-Moderate Resolution Imaging Spectroradiometer (MODIS) spacecraft over the Atlantic Ocean, J. Geophys. Res.-Atmos., 110, 1-16, https://doi.org/10.1029/2003JD004436, 2005.

Kim, D., Chin, M., Yu, H., Pan, X., Bian, H., Tan, Q., Kahn, R. A., Tsigaridis, K., Bauer, S. E., Takemura, T., Pozzoli, L., Bellouin, N., and Schulz, M.: Asian and TransPacific Dust: A Multimodel and Multiremote Sensing Observation Analysis, J. Geophys. Res.-Atmos., 124, 13534-13559, https://doi.org/10.1029/2019JD030822, 2019.

Kim, M. H., Omar, A. H., Tackett, J. L., Vaughan, M. A., Winker, D. M., Trepte, C. R., Hu, Y., Liu, Z., Poole, L. R., Pitts, M. C., Kar, J., and Magill, B. E.: The CALIPSO version 4 automated aerosol classification and lidar ratio selection algorithm, Atmos. Meas. Tech., 11, 6107-6135, https://doi.org/10.5194/amt11-6107-2018, 2018.

Klein, S. A. and Hartmann, D. L.: The Seasonal Cycle of Low Stratiform Clouds, J. Climate, 6, 1587-1606, https://doi.org/10.1175/1520 0442(1993)006<1587:TSCOLS>2.0.CO;2, 1993.

Klüser, L., Martynenko, D., and Holzer-Popp, T.: Thermal infrared remote sensing of mineral dust over land and ocean: a spectral SVD based retrieval approach for IASI, Atmos. Meas. Tech., 4, 757-773, https://doi.org/10.5194/amt-4-757-2011, 2011.

Kok, J. F., Ridley, D. A., Zhou, Q., Miller, R. L., Zhao, C., Heald, C. L., Ward, D. S., Albani, S., and Haustein, K.: Smaller desert dust cooling effect estimated from analysis of dust size and abundance, Nat. Geosci., 10, 274-278, https://doi.org/10.1038/ngeo2912, 2017.

Kurosaki, Y. and Mikami, M.: Recent frequent dust events and their relation to surface wind in East Asia, Geophys. Res. Lett., 30, 1736, https://doi.org/10.1029/2003GL017261, 2003.

Lau, K. M. and Kim, K. M.: Cooling of the Atlantic by Saharan dust, Geophys. Res. Lett., 34, L23811, https://doi.org/10.1029/2007gl031538, 2007.

Lee, E. H. and Sohn, B. J.: Recent increasing trend in dust frequency over Mongolia and Inner Mongolia regions and its association with climate and surface condition change, Atmos. Environ., 
45, 4611-4616, https://doi.org/10.1016/j.atmosenv.2011.05.065, 2011.

Levy, R. C., Mattoo, S., Munchak, L. A., Remer, L. A., Sayer, A. M., Patadia, F., and Hsu, N. C.: The Collection 6 MODIS aerosol products over land and ocean, Atmos. Meas. Tech., 6, 29893034, https://doi.org/10.5194/amt-6-2989-2013, 2013.

Levy, R. C., Mattoo, S., Sawyer, V., Shi, Y., Colarco, P. R., Lyapustin, A. I., Wang, Y., and Remer, L. A.: Exploring systematic offsets between aerosol products from the two MODIS sensors, Atmos. Meas. Tech., 11, 4073-4092, https://doi.org/10.5194/amt-11-4073-2018, 2018.

Li, W. J. and Shao, L. Y.: Observation of nitrate coatings on atmospheric mineral dust particles, Atmos. Chem. Phys., 9, $1863-$ 1871, https://doi.org/10.5194/acp-9-1863-2009, 2009.

Liu, Z., Sugimoto, N., and Murayama, T.: Extinction-to-backscatter ratio of Asian dust observed with high-spectral-resolution lidar and Raman lidar, Appl. Optics, 41, 2760-2767, 2002.

Marinou, E., Amiridis, V., Binietoglou, I., Tsikerdekis, A., Solomos, S., Proestakis, E., Konsta, D., Papagiannopoulos, N., Tsekeri, A., Vlastou, G., Zanis, P., Balis, D., Wandinger, U., and Ansmann, A.: Three-dimensional evolution of Saharan dust transport towards Europe based on a 9-year EARLINEToptimized CALIPSO dataset, Atmos. Chem. Phys., 17, 58935919, https://doi.org/10.5194/acp-17-5893-2017, 2017.

Martins, J. V., Tanré, D., Remer, L., Kaufman, Y., Mattoo, S., and Levy, R.: MODIS cloud screening for remote sensing of aerosols over oceans using spatial variability, Geophys. Res. Lett., 29, MOD4-1-MOD4-4, https://doi.org/10.1029/2001GL013252, 2002.

Mbourou, G. N., Bertrand, J. J., and Nicholson, S. E.: The Diurnal and Seasonal Cycles of Wind-Borne Dust over Africa North of the Equator, J. Appl. Meteorol., 36, 868-882, https://doi.org/10.1175/15200450(1997)036<0868:TDASCO>2.0.CO;2, 1997.

Mielonen, T., Arola, A., Komppula, M., Kukkonen, J., Koskinen, J., De Leeuw, G., and Lehtinen, K. E. J.: Comparison of CALIOP level 2 aerosol subtypes to aerosol types derived from AERONET inversion data, Geophys. Res. Lett., 36, L18804, https://doi.org/10.1029/2009GL039609, 2009.

Miller, R. L. and Tegen, I.: Climate response to soil dust aerosols, J. Climate, 11, 3247-3267, https://doi.org/10.1175/15200442(1998)011<3247:Crtsda>2.0.Co;2, 1998.

Müller, D., Ansmann, A., Mattis, I., Tesche, M., Wandinger, U., Althausen, D., and Pisani, G.: Aerosol-type-dependent lidar ratios observed with Raman lidar, J. Geophys. Res.-Atmos., 112, D16202, https://doi.org/10.1029/2006JD008292, 2007.

Omar, A. H., Winker, D. M., Kittaka, C., Vaughan, M. A., Liu, Z., Hu, Y., Trepte, C. R., Rogers, R. R., Ferrare, R. A., Lee, K. P., Kuehn, R. E., and Hostetler, C. A.: The CALIPSO automated aerosol classification and lidar ratio selection algorithm, J. Atmos. Ocean. Tech., 26, 1994-2014, https://doi.org/10.1175/2009JTECHA1231.1, 2009.

Omar, A. H., Winker, D. M., Tackett, J. L., Giles, D. M., Kar, J., Liu, Z., Vaughan, M. A., Powell, K. A., and Trepte, C. R.: CALIOP and AERONET aerosol optical depth comparisons: One size fits none, J. Geophys. Res.-Atmos., 118, 4748-4766, https://doi.org/10.1002/jgrd.50330, 2013.

O’Neill, N. T., Eck, T. F., Smirnov, A., Holben, B. N., and Thulasiraman, S.: Spectral discrimination of coarse and fine mode optical depth, J. Geophys. Res.-Atmos., 108, 4559, https://doi.org/10.1029/2002jd002975, 2003.

Painter, T. H., Barrett, A. P., Landry, C. C., Neff, J. C., Cassidy, M. P., Lawrence, C. R., McBride, K. E., and Farmer, G. L.: Impact of disturbed desert soils on duration of mountain snow cover, Geophys. Res. Lett., 34, L12502, https://doi.org/10.1029/2007GL030284, 2007.

Parrington, J. R., Zoller, W. H., and Aras, N. K.: Asian Dust: Seasonal Transport to the Hawaiian Islands, Science, 220, 195-197, https://doi.org/10.1126/science.220.4593.195, 1983.

Proestakis, E., Amiridis, V., Marinou, E., Georgoulias, A. K., Solomos, S., Kazadzis, S., Chimot, J., Che, H., Alexandri, G., Binietoglou, I., Daskalopoulou, V., Kourtidis, K. A., de Leeuw, G., and van der A, R. J.: Nine-year spatial and temporal evolution of desert dust aerosols over South and East Asia as revealed by CALIOP, Atmos. Chem. Phys., 18, 1337-1362, https://doi.org/10.5194/acp-18-1337-2018, 2018.

Prospero, J. M., Ginoux, P., Torres, O., Nicholson, S. E., and Gill, T. E.: Environmental characterization of global sources of atmospheric soil dust identified with the Nimbus 7 Total Ozone Mapping Spectrometer (TOMS) absorbing aerosol product, Rev. Geophys., 40, 2-1-2-31, https://doi.org/10.1029/2000RG000095, 2002.

$\mathrm{Pu}, \mathrm{B}$. and Ginoux, P.: How reliable are CMIP5 models in simulating dust optical depth?, Atmos. Chem. Phys., 18, 12491-12510, https://doi.org/10.5194/acp-18-12491-2018, 2018.

Qian, W., Quan, L., and Shi, S.: Variations of the dust storm in China and its climatic control, J. Climate, 15, 1216-1229, https://doi.org/10.1175/15200442(2002)015<1216:VOTDSI>2.0.CO;2, 2002.

Querol, X., Tobías, A., Pérez, N., Karanasiou, A., Amato, F., Stafoggia, M., García-Pando, C. P., Ginoux, P., Forastiere, F., and Gumy, S.: Monitoring the impact of desert dust outbreaks for air quality for health studies, Environ. Int., 130, 104867, https://doi.org/10.1016/j.envint.2019.05.061, 2019.

Rajapakshe, C., Zhang, Z., Yorks, J. E., Yu, H., Tan, Q., Meyer, K., Platnick, S., and Winker, D. M.: Seasonally transported aerosol layers over southeast Atlantic are closer to underlying clouds than previously reported, Geophys. Res. Lett., 44, 5818-5825, 2017.

Reichle, R. H., Liu, Q., Koster, R. D., Draper, C. S., Mahanama, S. P. P., and Partyka, G. S.: Land Surface Precipitation in MERRA2, J. Climate, 30, 1643-1664, https://doi.org/10.1175/JCLI-D16-0570.1, 2017.

Remer, L. A., Kaufman, Y. J., Tanre, D., Mattoo, S., Chu, D. A., Martins, J. V, Li, R. R., Ichoku, C., Levy, R. C., Kleidman, R. G., Eck, T. F., Vermote, E., and Holben, B. N.: The MODIS aerosol algorithm, products, and validation, J. Atmos. Sci., 62, 947-973, https://doi.org/10.1175/Jas3385.1, 2005.

Ridley, D. A., Heald, C. L., Kok, J. F., and Zhao, C.: An observationally constrained estimate of global dust aerosol optical depth, Atmos. Chem. Phys., 16, 15097-15117, https://doi.org/10.5194/acp-16-15097-2016, 2016.

Rosenfeld, D. and Lensky, I. M.: Satellite-based insights into precipitation formation processes in continental and maritime convective clouds, B. Am. Meteorol. Soc., 79, 2457-2476, https://doi.org/10.1175/15200477(1998)079<2457:Sbiipf>2.0.Co;2, 1998 
Sakai, T., Nagai, T., Zaizen, Y., and Mano, Y.: Backscattering linear depolarization ratio measurements of mineral, sea-salt, and ammonium sulfate particles simulated in a laboratory chamber, Appl. Optics, 49, 4441-4449, 2010.

Sayer, A. M., Hsu, N. C., Bettenhausen, C., and Jeong, M. J.: Validation and uncertainty estimates for MODIS Collection 6 "deep Blue" aerosol data, J. Geophys. Res.-Atmos., 118, 7864-7872, https://doi.org/10.1002/jgrd.50600, 2013.

Schuster, G. L., Vaughan, M., MacDonnell, D., Su, W., Winker, D., Dubovik, O., Lapyonok, T., and Trepte, C.: Comparison of CALIPSO aerosol optical depth retrievals to AERONET measurements, and a climatology for the lidar ratio of dust, Atmos. Chem. Phys., 12, 7431-7452, https://doi.org/10.5194/acp12-7431-2012, 2012.

Shao, Y. P., Wyrwoll, K. H., Chappell, A., Huang, J. P., Lin, Z. H., McTainsh, G. H., Mikami, M., Tanaka, T. Y., Wang, X. L., and Yoon, S.: Dust cycle: An emerging core theme in Earth system science, Aeolian Res., 2, 181-204, https://doi.org/10.1016/j.aeolia.2011.02.001, 2011.

Shimizu, A., Sugimoto, N., Matsui, I., Arao, K., Uno, I., Murayama, T., Kagawa, N., Aoki, K., Uchiyama, A., and Yamazaki, A. A.: Continuous observations of Asian dust and other aerosols by polarization lidars in China and Japan during ACE-Asia, J. Geophys. Res.-Atmos., 109, D19S17, https://doi.org/10.1029/2002JD003253, 2004.

Shimizu, A., Sugimoto, N., Nishizawa, T., Jin, Y., and Batdorj, D.: Variations of dust extinction coefficient estimated by lidar observations over Japan, 2007-2016, Sci. Online Lett. Atmos., 13, 205-208, https://doi.org/10.2151/sola.2017-037, 2017.

Song, H., Zhang, K., Piao, S., and Wan, S.: Spatial and temporal variations of spring dust emissions in northern China over the last 30 years, Atmos. Environ., 126, 117-127, 2016.

Song, Q., Zhang, Z., Yu, H., Kato, S., Yang, P., Colarco, P., Remer, L. A., and Ryder, C. L.: Net radiative effects of dust in the tropical North Atlantic based on integrated satellite observations and in situ measurements, Atmos. Chem. Phys., 18, 11303-11322, https://doi.org/10.5194/acp-18-11303-2018, 2018.

Song, Q., Yu, H., and Ginoux, P.: The global DAOD and dust vertical extinction coefficient climatology data derived from CALIOP in this study and the MODIS DAOD retrieval data over land and ocean [data set], available at: https://drive.google.com/drive/folders/ 1aQVupe7govPwR6qmsqUbR4fJQsp1DBCX?usp=sharing, last access: 9 Fenruary 2021.

Sternberg, T., Rueff, H., and Middleton, N.: Contraction of the Gobi desert, 2000-2012, Remote Sens., 7, 1346-1358, https://doi.org/10.3390/rs70201346, 2015.

Su, L. and Toon, O. B.: Saharan and Asian dust: similarities and differences determined by CALIPSO, AERONET, and a coupled climate-aerosol microphysical model, Atmos. Chem. Phys., 11, 3263-3280, https://doi.org/10.5194/acp-11-3263-2011, 2011.

Tan, I., Storelvmo, T., and Choi, Y.-S.: Spaceborne lidar observations of the ice-nucleating potential of dust, polluted dust, and smoke aerosols in mixed-phase clouds, J. Geophys. Res.-Atmos., 119, 6653-6665, https://doi.org/10.1002/2013JD021333, 2014.

Tang, M., Zhang, H., Gu, W., Gao, J., Jian, X., Shi, G., Zhu, B., Xie, L., Guo, L., Gao, X., Wang, Z., Zhang, G., and Wang, X.: Hygroscopic Properties of Saline Mineral Dust From Different Regions in China: Geographical Variations, Compositional Dependence, and Atmospheric Implications, J. Geophys. Res.-Atmos., 124, 10844-10857, https://doi.org/10.1029/2019JD031128, 2019.

Tesche, M., Ansmann, A., Müller, D., Althausen, D., Engelmann, R., Freudenthaler, V., and Groß, S.: Vertically resolved separation of dust and smoke over Cape Verde using multiwavelength Raman and polarization lidars during Saharan Mineral Dust Experiment 2008, J. Geophys. Res.-Atmos., 114, D13202, https://doi.org/10.1029/2009JD011862, 2009.

Textor, C., Schulz, M., Guibert, S., Kinne, S., Balkanski, Y., Bauer, S., Berntsen, T., Berglen, T., Boucher, O., Chin, M., Dentener, F., Diehl, T., Easter, R., Feichter, H., Fillmore, D., Ghan, S., Ginoux, P., Gong, S., Grini, A., Hendricks, J., Horowitz, L., Huang, P., Isaksen, I., Iversen, I., Kloster, S., Koch, D., Kirkevåg, A., Kristjansson, J. E., Krol, M., Lauer, A., Lamarque, J. F., Liu, X., Montanaro, V., Myhre, G., Penner, J., Pitari, G., Reddy, S., Seland, Ø., Stier, P., Takemura, T., and Tie, X.: Analysis and quantification of the diversities of aerosol life cycles within AeroCom, Atmos. Chem. Phys., 6, 1777-1813, https://doi.org/10.5194/acp-6-17772006, 2006.

Thorsen, T. J. and Fu, Q.: CALIPSO-inferred aerosol direct radiative effects: Bias estimates using ground-based raman lidars, J. Geophys. Res., 120, 12209-12220, https://doi.org/10.1002/2015JD024095, 2015.

Twomey, S.: The influence of pollution on the shortwave albedo of clouds, J. Atmos. Sci., 34, 1149-1152, 1977.

Uno, I., Eguchi, K., Yumimoto, K., Takemura, T., Shimizu, A., Uematsu, M., Liu, Z., Wang, Z., Hara, Y., and Sugimoto, N.: Asian dust transported one full circuit around theglobe, Nat. Geosci., 2, 557-560, https://doi.org/10.1038/ngeo583, 2009.

Voss, K. J., Welton, E. J., Quinn, P. K., Johnson, J., Thompson, A. M., and Gordon, H. R.: Lidar measurements during Aerosols99, J. Geophys. Res.-Atmos., 106, 20821-20831, 2001.

Voss, K. K. and Evan, A. T.: A new satellite-based global climatology of dust aerosol optical depth, J. Appl. Meteorol. Clim., 59, 83-102, 2020.

Winker, D. M., Vaughan, M. A., Omar, A., Hu, Y., Powell, K. A., Liu, Z., Hunt, W. H., and Young, S. A.: Overview of the CALIPSO Mission and CALIOP Data Processing Algorithms, J. Atmos. Ocean. Tech., 26, 2310-2323, https://doi.org/10.1175/2009JTECHA1281.1, 2009.

Winker, D. M., Pelon, J., Coakley, J. A., Ackerman, S. A., Charlson, R. J., Colarco, P. R., Flamant, P., Fu, Q., Hoff, R. M., Kittaka, C., Kubar, T. L., Le Treut, H., McCormick, M. P., Megie, G., Poole, L., Powell, K., Trepte, C., Vaughan, M. A., and Wielicki, B. A.: THE CALIPSO MISSION A Global 3D View of Aerosols and Clouds, Bull. Am. Meteorol. Soc., 91, 1211-1229, https://doi.org/10.1175/2010bams3009.1, 2010.

Winker, D. M., Tackett, J. L., Getzewich, B. J., Liu, Z., Vaughan, M. A., and Rogers, R. R.: The global 3-D distribution of tropospheric aerosols as characterized by CALIOP, Atmos. Chem. Phys., 13, 3345-3361, https://doi.org/10.5194/acp-133345-2013, 2013.

Wu, C., Lin, Z., and Liu, X.: The global dust cycle and uncertainty in CMIP5 (Coupled Model Intercomparison Project phase 5) models, Atmos. Chem. Phys., 20, 10401-10425, https://doi.org/10.5194/acp-20-10401-2020, 2020a.

Wu, M., Liu, X., Yu, H., Wang, H., Shi, Y., Yang, K., Darmenov, A., Wu, C., Wang, Z., Luo, T., Feng, Y., and Ke, Z.: Understanding processes that control dust spatial distributions with 
global climate models and satellite observations, Atmos. Chem. Phys., 20, 13835-13855, https://doi.org/10.5194/acp-20-138352020, 2020b.

Wu, T., Li, Z., Chen, J., Wang, Y., Wu, H., Jin, X., Liang, C., Li, S., Wang, W., and Cribb, M.: Hygroscopicity of different types of aerosol particles: Case studies using multiinstrument data in megacity Beijing, China, Remote Sens., 12, 785, https://doi.org/10.3390/rs12050785, 2020c.

$\mathrm{Xu}, \mathrm{H}$., Zheng, F., and Zhang, W.: Variability in dust observed over China using a-train caliop instrument, Adv. Meteorol., 2016, 1246590, https://doi.org/10.1155/2016/1246590, 2016.

Yang, W., Marshak, A., Várnai, T., Kalashnikova, O. V., and Kostinski, A. B.: CALIPSO observations of transatlantic dust: vertical stratification and effect of clouds, Atmos. Chem. Phys., 12, 11339-11354, https://doi.org/10.5194/acp-12-11339-2012, 2012.

Yorks, J. E., Palm, S. P., Hlavka, D. L., McGill, M. J., Nowottnick, E., Selmer, P., and Hart, W. D.: The Cloud-Aerosol Transport System (CATS) algorithm theoretical basis document, available at: http://cats.gsfc.nasa.gov/media/docs/CATS_ATBD.pdf (last access: 7 September 2021), 2015.

Young, S. A., Vaughan, M. A., Garnier, A., Tackett, J. L., Lambeth, J. D., and Powell, K. A.: Extinction and optical depth retrievals for CALIPSO's Version 4 data release, Atmos. Meas. Tech., 11, 5701-5727, https://doi.org/10.5194/amt-11-5701-2018, 2018.

Yu, H., Chin, M., Remer, L. A., Kleidman, R. G., Bellouin, N., Bian, H., and Diehl, T.: Variability of marine aerosol fine-mode fraction and estimates of anthropogenic aerosol component over cloud-free oceans from the Moderate Resolution Imaging Spectroradiometer (MODIS), J. Geophys. Res.-Atmos., 114, 1-11, https://doi.org/10.1029/2008JD010648, 2009.

Yu, H., Chin, M., Winker, D. M., Omar, A. H., Liu, Z., Kittaka, C., and Diehl, T.: Global view of aerosol vertical distributions from CALIPSO lidar measurements and GOCART simulations: Regional and seasonal variations, J. Geophys. Res.-Atmos., 115, 1-19, https://doi.org/10.1029/2009JD013364, 2010.

Yu, H., Remer, L. A., Chin, M., Bian, H., Tan, Q., Yuan, T., and Zhang, Y.: Aerosols from overseas rival domestic emissions over North America, Science, 337, 566-569, 2012.

Yu, H., Remer, L. A., Kahn, R. A., Chin, M., and Zhang, Y.: Satellite perspective of aerosol intercontinental transport: From qualitative tracking to quantitative characterization, Atmos. Res., 124, 73-100, https://doi.org/10.1016/j.atmosres.2012.12.013, 2013.

Yu, H., Tan, Q., Chin, M., Remer, L. A., Kahn, R. A., Bian, H., Kim, D., Zhang, Z., Yuan, T., Omar, A. H., Winker, D. M., Levy, R. C., Kalashnikova, O., Crepeau, L., Capelle, V., and Chédin, A.: Estimates of African Dust Deposition Along the Trans-Atlantic Transit Using the Decadelong Record of Aerosol Measurements from CALIOP, MODIS, MISR, and IASI, J. Geophys. Res.-Atmos., 124, 7975-7996, https://doi.org/10.1029/2019JD030574, 2019.
Yu, H., Yang, Y., Wang, H., Tan, Q., Chin, M., Levy, R. C., Remer, L. A., Smith, S. J., Yuan, T., and Shi, Y.: Interannual variability and trends of combustion aerosol and dust in major continental outflows revealed by MODIS retrievals and CAM5 simulations during 2003-2017, Atmos. Chem. Phys., 20, 139-161, https://doi.org/10.5194/acp-20-139-2020, 2020.

Yu, H., Tan, Q., Zhou, L., Zhou, Y., Bian, H., Chin, M., Ryder, C. L., Levy, R. C., Pradhan, Y., Shi, Y., Song, Q., Zhang, Z., Colarco, P. R., Kim, D., Remer, L. A., Yuan, T., Mayol-Bracero, O., and Holben, B. N.: Observation and modeling of the historic "Godzilla" African dust intrusion into the Caribbean Basin and the southern US in June 2020, Atmos. Chem. Phys., 21, 1235912383, https://doi.org/10.5194/acp-21-12359-2021, 2021.

Yu, H. B., Chin, M., Bian, H. S., Yuan, T. L., Prospero, J. M., Omar, A. H., Remer, L. A., Winker, D. M., Yang, Y. K., Zhang, Y., and Zhang, Z. B.: Quantification of trans-Atlantic dust transport from seven-year (2007-2013) record of CALIPSO lidar measurements, Remote Sens. Environ., 159, 232-249, https://doi.org/10.1016/j.rse.2014.12.010, 2015a.

Yu, H. B., Chin, M., Yuan, T. L., Bian, H. S., Remer, L. A., Prospero, J. M., Omar, A., Winker, D., Yang, Y. K., Zhang, Y., Zhang, Z. B., and Zhao, C.: The fertilizing role of African dust in the Amazon rainforest: A first multiyear assessment based on data from Cloud-Aerosol Lidar and Infrared Pathfinder Satellite Observations, Geophys. Res. Lett., 42, 1984-1991, https://doi.org/10.1002/2015gl063040, 2015b.

Yu, Y., Kalashnikova, O. V., Garay, M. J., and Notaro, M.: Climatology of Asian dust activation and transport potential based on MISR satellite observations and trajectory analysis, Atmos. Chem. Phys., 19, 363-378, https://doi.org/10.5194/acp-19-3632019, 2019.

Yu, Y., Kalashnikova, O. V., Garay, M. J., Lee, H., Choi, M., Okin, G. S., Yorks, J. E., Campbell, J. R., and Marquis, J.: A global analysis of diurnal variability in dust and dust mixture using CATS observations, Atmos. Chem. Phys., 21, 1427-1447, https://doi.org/10.5194/acp-21-1427-2021, 2021.

Yue, X., Wang, H., Wang, Z., and Fan, K.: Simulation of dust aerosol radiative feedback using the Global Transport Model of Dust: 1. Dust cycle and validation, J. Geophys. Res.-Atmos., 114, D10202, https://doi.org/10.1029/2008JD010995, 2009. 